\title{
ESTADO CONSTITUCIONAL Y GOBERNANZA: BASES PARA UNA APERTURA DEMOCRÁTICA DE LAS POLÍTICAS PÚBLICAS EN MÉXICO*
}

\section{CONSTITUTIONAL STATE AND GOVERNANCE: PLATFORM FOR A DEMOCRATIC OPENNESS OF PUBLIC POLICIES IN MEXICO}

\author{
Joaquín Ordóñez-Sedeño** \\ Isaac De Paz-González*** \\ Fecha de recepción: 11 de octubre de 2016 \\ Fecha de aceptación: 25 de enero de 2017 \\ Disponible en línea: 30 de mayo de 2017
}

\section{Para citar este artículo/To cite this article}

\begin{abstract}
Ordóñez-Sedeño, Joaquín \& De Paz-González, Isaac, Estado constitucional y gobernanza: bases para una apertura democrática de las políticas públicas en México, 134 Vniversitas, 169-208 (2017). http://dx.doi. org/10.11144/Javeriana.vj134.ecgb doi:10.11144/Javeriana.vj134.ecgb
\end{abstract}

* Este artículo forma parte del proyecto de investigación del Consejo Nacional de Ciencia y Tecnología, CONACYT (CB/156846), bajo la responsabilidad del Cuerpo Académico consolidado Estudios Constitucionales de la Facultad de Derecho de la Universidad Autónoma del Estado de México, UAEMex.

** Doctor en derecho, Universidad Autónoma del Estado de México, UAEMex. Profesor e investigador de tiempo completo, Facultad de Derecho, Universidad Autónoma del Estado de México, UAEMex. Miembro del Cuerpo Académico consolidado Estudios Constitucionales. Miembro del Sistema Nacional de Investigadores, SNI. Contacto: joaquin.o@me.com

*** Profesor-investigador de tiempo completo de la Universidad Autónoma Baja California. Miembro del Sistema Nacional de Investigadores, SNI. Miembro de The Society of Legal Scholars. Doctor en derechos fundamentales y libertades públicas, Cum Laude, Universidad de Castilla-La Mancha, UCLM, España. Contacto: isaac.depaz@uabc.edu.mx 


\section{RESUMEN}

Se da por hecho que un Estado es "constitucional", porque tiene un cuerpo normativo que establece la estructura de gobierno, que reconoce como objetivo primordial los derechos humanos y que expresa mecanismos de control del poder a favor del pueblo. Sin embargo, sin un entramado democrático, las normas no garantizan que sus fines se cumplan. México ha tenido diversas reformas constitucionales que no han logrado cumplir su cometido. En este contexto, el trabajo alude que la crisis institucional, económica y de derechos humanos en México no se solucionará con reformas, sino mediante una reorientación de los actores implicados en los sectores políticos, administrativos y de administración de justicia. Asimismo, como aporte, el artículo propone nuevas líneas de acción para mejorar la gobernanza con bases y objetivos participativos; que hagan realidad las disposiciones jurídicas, económicas y políticas de la Constitución.

Palabras clave: poderes públicos; participación política; apertura institucional; mecanismos de gobernanza 


\section{ABSTRACT}

It is assumed that the rule of law is guaranteed by the Constitution; the regulatory body that establishes the structure of government, recognizes the primary objective of human rights, and expresses control mechanisms related to the empowerment of the people. However, without a democratic framework, the regulations do not guarantee that their goals are met. Mexico has had various constitutional reforms that have failed to fulfil their missions. In this context, this work argues that the institutional, economic, and human rights crisis in Mexico will not be solved with "legal reforms", but by the accompaniment of a reorientation of the actors involved in the political, administrative, and justice sectors. Also, as input, the article proposes new lines of action to improve governance and participatory bases in order to make a reality of the legal, economic, and political provisions of the Constitution.

Keywords: public powers; political participation; institutional openness; governance mechanisms

\section{SUMARIO}

Planteamiento.- I. Más allá del Estado constitucional.- $A$. Evitar la tiranía.- B. Dar viabilidad política a los derechos esenciales.- C. Garantizar la libertad política y personal.- D. Procurar la autodeterminación y contribuir al desarrollo humano.- II. DEMOCRACIA DELIBERATIVA: ¿PARA QUÉ?III. Sujetos, ACtores y problemas De Gobernanza.- A. Marco y factores internos.- B. Marco y factores externos.- C. Gobernanza posnacional.- IV. PolíticAs PÚblicas: DEMOCRATIZACIÓN DE LA GOBERNANZA.- CONCLUSIONES.Bibliografía. 


\section{PLANTeamiento}

En la teoría constitucional y la ciencia política, la concepción normativa y axiológica del Estado constitucional constituye un referente ineludible para el estudio de los derechos y las políticas como fines que una sociedad justa persigue, para lo que hay diversos estudios ${ }^{1}$ que ya son un lugar común y tienen como sustrato las reflexiones que buscan reorientar — con cualidad más autoritativa - la dignidad humana con una visión antropocéntrica de la sociedad política para la reconstrucción del Estado desde abajo con una dosis alta de legitimación (popular); la protección de los débiles, y al hombre situado ${ }^{2}$ para el desarrollo de sus capacidades.

En esta arena teórica, consideramos oportuno establecer la conexión que hay entre este bagaje teórico y la realidad del Estado mexicano en su dimensión funcional. La necesidad de este replanteamiento hacia los problemas es una respuesta estatal y social (reactiva); que, a su vez, muestra la mutación del tipo de sociedad política y la diversificación de entes (públicos y privados) que tienen influencia - en las relaciones de poder, y en consecuencia- en las decisiones que afectan o benefician a la sociedad.

El objetivo de este trabajo es reconocer la necesidad de reorganizar las bases conceptuales del Estado mexicano - como concepto político y jurídico - y plantear una nueva forma de articular las

1 Los estudios históricamente influyentes del concepto del Estado con fines sociales, provienen de la formación del Reichstaat alemán de finales del siglo XIX; de las cualidades políticas que dieron origen a The Rule of Law and Not of Men; del gobierno bajo la "razón de las leyes" y de la isonomía (igualdad-equidad) ante la ley. Sobre estos puntos, y con énfasis en las ideas de la racionalidad de la legislación: Imer Benjamín Flores-Mendoza, Law, Liberty and the Rule of Law (in a Constitutional Democracy), en Law, Liberty, and The Rule of Law, 77-101 (Imer Benjamín Flores-Mendoza \& Kenneth Einar Himma, eds., Springer Science+Business Media, Dordrecht, Netherlands, 2013). Asimismo, Tom Bingham describe los principios y diversas cualidades del concepto de Rule of Law, que está relacionado con los siguientes postulados: La ley deberá ser clara, accesible e inteligible; la ley debe permitir protección adecuada hacia los derechos fundamentales (como concepto interconectado con la democracia); la obligatoriedad de los servidores públicos de ejercer el poder bajo límites razonables y el cumplimiento de los Estados con sus obligaciones de Derecho Internacional. Cfr. Tom Bingham, The Rule of Law (Centre for Public Law, The Sixth Sir David Williams Lecture, $16^{\text {th }}$ November 2006). Disponible en: http://www.cpl.law.cam.ac.uk/sir-david-williams-lectures/ rt-hon-lord-bingham-cornhill-kg-rule-law

2 Entre otras, la idea del hombre situado es construida por Georges Burdeau, cuya obra estuvo enfocada en exaltar la importancia de la democracia gobernada en torno a políticas públicas elaboradas con legitimidad social; esto implica que la libertad de los gobernantes está sujeta a la libertad de los gobernados. GEORGEs BurdeAu, Écrits de Droit constitutionnel et de Science politique, Textes réunis et préfacés par Jean Marie Denquin (ChARLes LeBen, dir., Éditions Panthéon Assas, Collection Les introuvables, Paris, 2011). 
decisiones de los gobernantes. Entendiendo por gobernantes no solo los típicos poderes públicos (legislativo, judicial y ejecutivo) sino los organismos públicos que tienen autonomía ${ }^{3}$. De esta manera, en los siguientes apartados abordaremos la delimitación de la democracia deliberativa ${ }^{4}$ como uno de los renglones importantes para la cohesión y legitimación del Estado constitucional. Enseguida, se analizará el tema de la gobernanza: sus marcos, actores e implicaciones. Finalmente, haremos una síntesis de las líneas sugeridas para que las decisiones de Estado (que en general constituyen política pública) contengan ingredientes democráticos en el sentido de apertura, diálogo, coordinación y especialización de las decisiones, de acuerdo a los objetivos, que en este momento histórico, son necesarios.

\section{MÁs ALLÁ del ESTADo CONSTITUCIONAL}

Tradicionalmente, la doctrina ha considerado que el Estado Constitucional es el más acabado de la producción organizativa del ser humano, se trata de una cúspide estructural-social que establece, de forma definitiva, las bases para el funcionamiento de una sociedad. Desde los clásicos, se afirmaba la importancia de la Constitución en un Estado; aunque más tarde se advertía que "no todo Estado es Estado de Derecho"5. En efecto, estamos tan involucrados e inmersos en las teorías de los clásicos que damos por sentado que los Estados constitucionales formalmente lo son también en su realidad social; sin embargo, cabe cuestionar: jla existencia de constituciones vigentes en los Estados es un parámetro para considerar que son Estados constitucionales propiamente dichos? La respuesta exige una

3 Como el Instituto Nacional Electoral, INE; la Comisión Nacional de Derechos Humanos, CNDH; el Banco de México, BANXICO; la Auditoría Superior de la Federación, ASF; el Instituto Federal de Telecomunicaciones, IFT.

4 Respecto de esta forma de democracia más abierta, Isaac de Paz-González y Arturo Garita-Alonso afirman que la democracia constitucional es un enfoque del constitucionalismo objetivo y crítico, que busca un modelo de Estado en el que las normas políticas y de derechos humanos no estén sujetas a marcos rígidos - o excluyentes - de vinculación, sino que todos los órganos de Estado y agentes de poder sean artífices más activos. Isaac de Paz-González \& Arturo Garita-Alonso, Discusión democrática: nuevos derroteros en el Parlamento mexicano, en El derecho parlamentario mexicano. Una visión de actualidad, 115 (Enrique Uribe-ArZate \& Joaquín Ordóñez-Sedeño, AM Editores y Universidad Autónoma del Estado de México, México, 2015). Disponible en: https://www. academia.edu/15126416/Discusi\%C3\%B3n_democr\%C3\%A1tica_nuevos_derroteros_en_el_Parlamento mexicano

5 Elías Díaz, Estado de Derecho y sociedad democrática, 4 (Taurus, Madrid, 1966). 
revisión empírica delimitada a ciertas geografías constitucionales, reconociendo que muchos de ellos están en construcción ${ }^{6} \mathrm{y}$, como en el caso de México, que las reformas constitucionales no necesariamente permean en la sociedad política ni modifican patrones o vicios institucionales.

En consecuencia, los hechos y fenómenos sociales de actualidad en México (y en el mundo) muestran que el problema no se limita a poder válidamente considerar un Estado como constitucional por su dimensión formal o normativa. Por ello, hoy más que nunca subsiste la necesidad de aclarar las cualidades constitucionales y sociales de los documentos normativos, sobre todo para lograr consensos constitucionales legítimos ${ }^{7}$ y poder edificar las bases societarias e institucionales de las disposiciones constitucionales.

Otra de las preguntas (quizá la más dolorosa en términos de problemática social mexicana) es aquella relacionada con el planteamiento de la necesidad de "reformar el Estado". De las reformas de Estado, mucho se habla pero el ciudadano común no vive en un Estado que le proporcione la seguridad física, económica, educativa o que le augure un futuro claro. Estas condiciones negativas son aludidas por diversas fuentes doctrinales e incluso periodísticas que cuestionan la falla técnica del Estado en aspectos fundamentales y cotidianos ${ }^{8}$.

Es tan alarmante la situación que resulta necesario plantearse: ¿el Estado mexicano tiene indicadores de un Estado Fallido? No nos detendremos en la cuestión fáctica o doctrinal (desde la pers-

6 Probablemente, los casos más conocidos sean Ecuador y Bolivia. En América Latina, hay un avance normativo respecto de las nuevas constituciones como intento de transformación de las condiciones de desigualdad. Este es un rasgo muy especial del Ius Constitutionale Commune latinoamericano, según Armin von Bogdandy, Ius Constitutionale Commune en América Latina: una mirada a un constitucionalismo transformador, 34 Revista Derecho del Estado, 3-50 (2015). Disponible en: http://revistas.uexternado.edu.co/index.php/derest/article/view/4198/4643

7 Desde 2005, vimos cómo en la Unión Europea (mediante la no ratificación popular de Irlanda, Holanda y Francia) surgió el rechazo a una Constitución corporativa. Sobre este punto, se dice que era necesario tomar en cuenta las "identidades nacionales y constitucionales" de los Estados parte. M. F. Leonard Besselink, National and Constitutional Identity before and after Lisbon, 6 Utrecht Law Review, 3, 36-49 (2010). Disponible en: https://www.utrechtlawreview.org/articles/ abstract/10.18352/ulr.139/

8 Como una muestra de este sentir social y mediático, en el noticiario del 6 de octubre de 2015 (horario 6-9 a.m.), en el programa 88.9 Noticias, en frecuencia modulada, con Iñaki Manero, se plantearon estas preguntas al público: ¿Cuánto ha invertido usted en su seguridad, alarma, caseta de policía, vigilancia vecinal, remodelación de puertas, ventanas? ¿Cree usted que el Estado está obligado a garantizar la seguridad de sus habitantes? ¿Quién debe pagar la seguridad: el Estado o los ciudadanos? 
pectiva internacional) acerca del failed state que, por lo general, se caracteriza por la desprotección generalizada de sus ciudadanos y por la transgresión a los derechos humanos en todos los aspectos, lo que genera como consecuencia, la intervención internacional ${ }^{9}$.

Lo que interesa aquí es reconocer que el discurso político $-\mathrm{y}$ también académico - se ha centrado en cuestionar la falta de medidas eficaces del Estado hacia sus problemas esenciales, como la seguridad, la corrupción, la estabilidad económica o la protección de los derechos humanos. Por otra parte, en el contexto de la transición de la democracia mexicana, ni la invocación del "Estado de derecho" o la "legalidad", ni la reforma de derechos humanos parecen satisfacer las críticas más simples contra la ausencia de gobernabilidad, porque los hechos ilustran que no se han cumplido los fines constitucionales en que se debe sustentar la actividad pública. Así, surge diverso cuestionamiento que no se plantea desde las estructuras políticas sino en el sentir popular: ${ }_{\mathrm{H}} \mathrm{Ha}$ fracasado el Estado mexicano en proteger la economía, otorgar los servicios públicos esenciales como la seguridad pública o la economía doméstica? Las respuestas se hallan en los resultados de las mediciones que el propio Estado hace de su gestión. No se han cumplido los objetivos de seguridad ni los sociales ${ }^{10}$.

Precisamente, por los datos duros que arrojan cifras de millones de personas en un estado de pobreza alimentaria, se ha considerado como un Estado con indicios de fallido ${ }^{11}$. Aunado a lo anterior, la problemática relativa a la seguridad pública es también un factor detonante para que nos cuestionemos acerca de la viabilidad y eficacia del llamado Estado constitucional mexicano; basta recordar los casos de violación a los derechos humanos en los feminicidios de Ciudad Juárez o el caso de los estudiantes desaparecidos de Ayotzinapa $^{12}$, lo cual nos da una idea justificativa del planteamiento en este

9 John Sebastián Zapata-Callejas, La teoría del estado fallido: entre aproximaciones y disensos, 9 Revista de Relaciones Internacionales, Estrategia y Seguridad, 1, 87-110 (2014). Disponible en: http://revistas.unimilitar.edu.co/index.php/ries/article/view/52

10 Así lo muestran, por ejemplo, el aumento de la percepción de inseguridad y los homicidios. México, Instituto Nacional de Estadística, Geografía e Informática, INEGI, Encuesta Nacional de Victimización y Percepción sobre Seguridad Pública, ENVIPE (2016). Disponible en: http://www.beta. inegi.org.mx/proyectos/enchogares/regulares/envipe/2016/

11 United Nations International Children's Emergency Fund, UNICEF México, Pobreza y desigualdad (Fondo de las Naciones Unidas para la Infancia, UNICEF). Disponible en: https://www.unicef.org/ mexico/spanish/17046.html

12 La incidencia delictiva nacional aumentó en 18\% de 2012 a 2013, lo que pone a México como uno 
apartado: un tema más allá del Estado constitucional que cuestione el statu quo de la teoría normativa frente a la realidad social en la que se ha aplicado. Para lo anterior, es necesario contrastar los postulados de las normas constitucionales y los resultados sociales que muestran una ruptura del discurso del cambio democrático y mayor abuso del poder con mecanismos pseudodemocráticos ${ }^{13}$.

Ahora bien, los factores que deben tomarse en cuenta para considerar un Estado como constitucional son:

\section{A. Evitar la tiranía}

En un Estado constitucional, la legitimación es indispensable para erradicar la tiranía ${ }^{14}$; que quienes detentan el poder o quienes ocupan cargos estatales o de interés público no tengan conductas de abuso. De lo contrario, el Estado retrocederá a la dictadura institucional que legaliza actos autoritarios. La Constitución, en su carácter de documento normativo fundamental, en el que se plasman las decisiones políticas y económicas fundamentales para la gobernanza de un Estado, es la brújula de la vida social. Pero también debe haber otro cuerpo normativo robusto, el que en mayor medida rige la vida institucional: la legislación reglamentaria en todo el subsistema de gobierno de las entidades federativas. En este aspecto, la responsabilidad de los agentes del Estado debe construirse en tres sectores: penal, administrativo y civil. En el contexto mexicano, una visión más coercitiva de la responsabilidad política debe suprimir los fueros a legisladores locales y federales, y gobernadores de las entidades federativas. Solo con ello se lograría una rendición de cuentas, pues la falta de controles favorece la corrupción y la distorsión de la democracia ${ }^{15}$.

de los más peligrosos del planeta, solo detrás de Somalia, Afganistán, Irak, Pakistán, Siria y Egipto.

13 Como el eufemismo de las elecciones libres, que en México son cooptadas por las agencias de gobierno que funcionan como oficinas de recaudación de votos por medio de los programas de apoyo social (de salud, dádivas en educación básica y apoyo a grupos vulnerables); y de los partidos políticos e inhibe la participación ciudadana.

14 La tiranía de los poderes públicos, de los agentes privados y de las empresas globales que en buena medida son responsables de violaciones a los derechos humanos.

15 Lucía Ramírez-López \& IsaAc Leobardo SÁnchez-Juárez, Crecimiento económico, corrupción e instituciones en México, 22 Nóesis. Revista de Ciencias Sociales y Humanidades, 43-1, 104-133, 115 (2013). Disponible en: http://erevistas.uacj.mx/ojs/index.php/noesis/article/view/255/240 


\section{B. Dar viabilidad política a los derechos esenciales}

En un Estado que se jacte de ser constitucional, se deben dejar claramente establecidos los derechos fundamentales; aquellos que permiten el óptimo funcionamiento del mismo, que sirvan de camino en el que se puedan conseguir las metas y finalidades comunes a la población. Lo anterior, aunque puede parecer una obviedad, no lo es. Las Constituciones políticas modernas han incluido un catálogo de derechos con esas características, o al menos con la pretensión de esas características. La desventaja es que el poder constituyente permanente reforma o adiciona a su voluntad la Constitución sin un verdadero afán transformador sino meramente formal. Por ello, la Constitución ha sufrido, con esas prácticas, una devaluación en cuanto a la fijación ( $\mathrm{y}$ a su contenido esencial) de preceptos, lo cual provoca que se les reste seriedad y legitimidad a los nuevos derechos adjetivados como fundamentales ${ }^{16}$. No obstante, para que el Estado funcione de manera óptima, es indispensable que se cumplan los presupuestos de fundamentalidad mencionados. En este aspecto, la viabilidad política consistiría en facilitar rutas no judiciales a la eficacia de los derechos, ya que su protección en las cortes no ha sido la óptima, pues el reiterado discurso de la judicialización de los derechos solo refleja su desobediencia y conflictividad por la ausencia de otros mecanismos de adjudicación.

\section{Garantizar la libertad política y personal}

La libertad es uno de los postulados fundamentales de la democracia, sin el cual no es posible hablar ni siquiera de una sociedad mínimamente civilizada. Se trata de una de las columnas que sostienen un Estado constitucional y que presupone la erradicación de las prácticas tiránicas y dictatoriales de los gobiernos. Sin embargo, no es suficiente con que haya reglas o normas que enuncien formalmente el derecho de libertad y sus derivados, sino que además es

16 Incluso, la clase gobernante ha llegado al extremo de llamarlos Derechos humanos sin que se reflexione sobre su contenido esencial, el cual debería ajustar a la conceptualización mínima de un derecho de ese tipo; por el contrario, la inclusión del mal llamado Derecho humano obedece a estándares políticos, posiblemente demagógicos o (peligrosamente) con fines electorales, al formar parte de un discurso fácil de ser aceptado, pero con pocas posibilidades de ser adjudicados en la realidad. 
indispensable que en el ámbito policial y judicial se reconozcan los instrumentos y mecanismos para: i) mejorar la identidad política de los gobernados, ii) evitar las prácticas invasivas de libertad como las detenciones arbitrarias o la "prisión oficiosa". Por otro lado, la libertad política se ve sofocada por las limitaciones económicas; las decisiones políticas se adaptan al miedo a la inseguridad.

\section{Procurar la autodeterminación y contribuir al desarrollo humano}

Los pueblos y las personas tienen derecho a la autodeterminación, esto es, el derecho de igualdad llevado a un plano social en el que los integrantes de una población tienen la libertad para asumir su condición política; proveer su desarrollo económico, social y cultural y disponer libremente de sus riquezas y recursos naturales ${ }^{17}$. Se trata de uno de los aspectos que también deben ser observados por los Estados que pretendan considerarse como constitucionales y democráticos; sobre esas bases, se pueden construir plataformas políticas y económicas tendientes al desarrollo humano de manera efectiva y con planes de trabajo que produzcan verdaderos resultados benéficos para la población.

En suma, más allá del discurso sobre el Estado constitucional es un planteamiento que se pretende sustentar en términos del desarrollo adecuado de la función y la relación Estado-sociedad, con la finalidad de que sean las necesidades contextualizadas de la población las que marquen la pauta al momento de estructurar y reestructurar su organización y funcionamiento. Lo anterior da pauta para que se aborde el tema del Estado constitucional y la gobernanza desde el punto de vista de la democracia deliberativa en un intento por reforzar las políticas públicas.

17 En el Pacto Internacional de los Derechos Económicos, Sociales y Culturales, adoptado para reconocer la dimensión obligatoria del empoderamiento económico. Organización de Naciones Unidas, ONU, Pacto Internacional de los Derechos Económicos, Sociales y Culturales, adoptado por la Asamblea General mediante la Resolución 2200A (XXI), 16 de diciembre de 1966. Disponible en: http://www.ohchr.org/SP/ProfessionalInterest/Pages/CESCR.aspx. En el Sistema Interamericano, se cuenta con el Protocolo de San Salvador, que desarrolla lo que dispone el artículo 26 de la Convención Americana de Derechos Humanos. Organización de Estados Americanos, OEA, Protocolo Adicional a la Convención Americana sobre Derechos Humanos en materia de Derechos Económicos, Sociales y Culturales, Protocolo de San Salvador, 17 de noviembre de 1988. Disponible en: http:// www.oas.org/juridico/spanish/tratados/a-52.html 


\section{DEMOCRACIA DELIBERATIVA: ¿PARA QUÉ?}

La democracia es uno de los instrumentos con los que cuenta el ser humano para poder tomar decisiones de carácter público, las cuales trascienden siempre hasta la comunidad general, parten desde la posición gubernamental y trazan un derrotero cuyo fin es la vida política, social y jurídica de un Estado. Se trata de una idea que, a pesar de las múltiples críticas que se le hacen, sigue siendo el mejor sistema para poder formar gobiernos y para esa toma de decisiones colectivas; y más aún: es el mejor instrumento con el que el ciudadano y el poder público cuentan para abonar la gobernanza en un Estado constitucional. En efecto, la democracia - como teoría y como práctica - incide de forma innegable en el ejercicio del poder público y en la práctica real de la función de gobernar, mediante de las políticas públicas que son el medio para lograr de la mejor manera el objetivo de los gobiernos: proporcionar una situación de bienestar y —en última instancia - de felicidad al elemento humano del Estado: el pueblo.

No obstante, también es necesario tener en cuenta que la democracia ha sufrido múltiples mutaciones. Se puede hablar de ella e, incluso, analizarla desde diversas aristas: económica, educacional, social, etc., lo cual exige hacerlo - en términos de la gobernanza y de las políticas públicas - desde su aspecto deliberativo y multidimensional.

El principio se erige de forma clara, ya que los obstáculos con los que se encuentra el ejercicio del gobierno - más aún, del buen gobierno - son determinantes para su resultado y dependen de la forma en la que se toman esas decisiones. Concretamente, es posible que las decisiones y discusiones sobre aspectos públicos solucionen mejor (o simplemente solucionen) los problemas sociales que aquejan a las personas en un Estado constitucional, ya que la deliberación pública les otorga legitimidad a las decisiones cuando son adoptadas por la ciudadanía en un ejercicio político y social de discusión racional, imparcial y abierta. Para fundamentar lo anterior, es necesario considerar lo analizado por Jürgen Habermas:

La noción de democracia deliberativa está enraizada en el ideal intuitivo de una asociación democrática en la que la justificación de los términos y condiciones de la asociación tienen lugar a través de la argumentación y del razonamiento 
público entre ciudadanos iguales. En tal orden los ciudadanos comparten el compromiso de resolver los problemas de elección colectiva mediante el razonamiento público y tienen sus instituciones básicas por legítimas en la medida en que estas establecen un marco para la deliberación pública libre ${ }^{18}$.

Hay dos factores importantes en la noción y análisis de la democracia deliberativa; por un lado, la argumentación y el razonamiento y, por otro lado, los ciudadanos iguales; se debe partir de ahí para una idea cabal de este aspecto de la democracia, que si bien es poco explorado es también vital para el desarrollo de un Estado y de sus políticas públicas.

De acuerdo con Habermas, la comunicación entre seres iguales no es posible sin el elemento - comunicativo también- de la argumentación; por ello, es necesario que en un acto de deliberación - inmerso en el diálogo interno - la discusión propositiva y el análisis crítico y contextualizado de los problemas contengan aspectos argumentativos. No sería posible pensar en una deliberación (que se aproxima lo suficiente a la discusión de ideas, a la reflexión de propuestas y al análisis de problemáticas) sin la debida argumentación de los sujetos comunicantes ni de aquellos inmersos en los problemas que son objeto de discusión. Por otro lado está el razonamiento público, considerado como una forma concreta de dilucidar los problemas de la sociedad y del Estado. Este razonamiento está compuesto de una diversidad de razonamientos individuales y hasta cierto punto aislados pues cada uno de ellos sustenta una postura producto de cada raciocinio particular y de cada situación específica vivida por el sujeto que la sustenta, y que, eventualmente, cobra vida en una homogeneización de razonamientos fundidos en uno solo (como la decisión electoral) ${ }^{19}$ para poder elevarlo a la categoría de decisión pública.

No menos importante es el otro factor, el de la ciudadanía igual, ya que la discusión y el razonamiento público deben ser producidos entre ciudadanos iguales, no desiguales; lo anterior es de suma importancia ya que se puede contrastar con los postulados de la teoría

18 Jürgen Habermas, Facticidad y validez. Sobre el derecho y el Estado democrático de derecho en términos de teoría del discurso, 381 (4a ed., Trotta, Madrid, 2005).

19 Desde luego, con mecanismos apropiados para ello: los procedimientos democráticos electorales, que funcionan de una manera más o menos similar en diferentes sociedades y tienen como meta la de hacer posible la colocación y posterior formación de los gobiernos necesarios para controlar y regular el presente y futuro de un Estado. 
de la democracia, en especial con aquel que sostiene la igualdad de todos para poder emitir una decisión pública, es decir, la igualdad decretada por la democracia sin que sea revisable aquella de facto que existe en la masa de ciudadanos, debido a factores objetivos y tangibles ${ }^{20}$ y que - en ciertas circunstancias - pudiera ser importante y revisable, pero que tratándose de la democracia deliberativa no lo es tanto.

Ahora bien, las instituciones básicas son legítimas si y solo si establecen un marco para la deliberación pública libre, ya que no basta con que la teoría de la democracia (deliberativa) nos presente una serie de opciones viables para la correcta y adecuada toma de decisiones en un Estado, sino que además es preciso que el propio ente estatal prevea la instauración de los mecanismos e instrumentos reales y factibles para que eso sea una realidad. No basta con tener una ciudadanía dispuesta y capacitada para emitir argumentos y razonamientos de calidad pública que resuelvan - o que analicen los problemas que la aquejan-, sino que también es necesario que esa manifestación sea producto del razonamiento, la discusión y la argumentación sean canalizadas debida y adecuadamente $-\mathrm{y}$ sin trabas - para que logren su finalidad y cumplan sus cometidos públicos.

Precisamente por lo anterior, Habermas manifiesta que la teoría del discurso cuenta con la intersubjetividad de orden superior que representan los procesos de entendimiento que se efectúan a través de los procedimientos democráticos o en la red de comunicación de los espacios públicos políticos ${ }^{21}$, y es entonces cuando el aspecto deliberativo de la democracia cobra una manifiesta importancia en el aspecto decisional de los asuntos públicos. En efecto, en una democracia lo esencial es la participación de los ciudadanos y la expresión de su voluntad en la conformación del gobierno; pero no solo eso: es de suma importancia que el ciudadano se vea involucrado en la actividad de los que detentan el poder público con la

20 Verbigracia, la posición económica, el nivel de estudios, el coeficiente intelectual, el color de piel, las creencias religiosas, etc. Estos factores han sido erradicados por la teoría de la democracia igualitaria, aquella que presenta el voto universal como un efecto del voto sensitivo y aquel que también es llamado de calidad, que causó estragos en las incipientes sociedades que utilizaban el voto como un medio para la toma de decisiones estatales.

21 Jürgen Habermas, Facticidad y validez. Sobre el derecho y el Estado democrático de derecho en términos de teoría del discurso, 375 (4a ed., Trotta, Madrid, 2005). 
finalidad de vigilarla, supervisarla e, incluso, regularla. Lo anterior conlleva un requisito insoslayable: el conocimiento que el ciudadano tenga respecto a la actividad gubernamental que va a supervisar o de la plataforma política que algún candidato está sosteniendo en su campaña; es decir, el elector necesita conocer la actividad y la ideología de quien es - y de quien pretende ser- - una figura pública.

Para ese conocimiento hay muchas alternativas que el ciudadano puede aprovechar, como los instrumentos legales que en materia de petición y de transparencia tiene el sistema jurídico, la asistencia a las campañas electorales, la atención a los medios de comunicación $\mathrm{y}$, desde luego, presenciar los debates; todo ello haría que el ciudadano estuviera informado y en aptitud de emitir un voto libre ${ }^{22}$.

Ahora bien, la importancia de que las instituciones establezcan un marco para la deliberación política libre radica en que, en caso contrario, podrían ser consideradas autoritarias e ilegítimas, y en la historia democrática de México ya se ha puesto a prueba el grado de compromiso democrático de los medios de comunicación (como un ejemplo de los instrumentos y medios que el Estado mexicano tiene a su alcance para hacer realidad una democracia deliberativa $)^{23}$. Se trata, desde luego, de un obstáculo a la consolidación democrática en México, pues no se ha favorecido la comunicación como un instrumento importante para la democracia deliberativa. En palabras de Habermas:

El desarrollo y consolidación de una política deliberativa, la teoría del discurso los hace depender, no de una ciudadanía colectivamente capaz de acción, sino de la institucionalización de los correspondientes procedimientos y presupuestos

22 Con los debates se puede presenciar la confrontación de planes, programas, ideas, sentimientos y propuestas de quienes aspiran a un cargo público; y todo en un formato en el que todos los aspirantes están reunidos en un mismo sitio y se comunican, argumentan, razonan, discuten, en una palabra: deliberan entre ellos sin intermediación de ningún tipo y bajo las reglas de temporalidad y formalidad establecidas, lo que produce la valiosa posibilidad — quizá irrepetible — de que se aclaren, demuestren y/o fundamenten todo tipo de argumentos, ideologías, posturas, acusaciones, etc., con el consecuente beneficio de que el ciudadano obtenga mayor información y pueda generar un mejor criterio que le servirá al momento de decidir la orientación de su voto.

23 Específicamente de los titulares de las concesiones, ya que para la elección federal de 2012 no todos los concesionarios aceptaron transmitir el debate entre los candidatos presidenciales y eso evitó que la información y el conocimiento generado en el mismo llegaran a la conciencia de muchos ciudadanos mexicanos. 
comunicativos, así como de la interacción de deliberaciones institucionalizadas con opiniones públicas desarrolladas informalmente ${ }^{24}$.

Pero la política y la democracia deliberativas no son posibles sin el cumplimiento de los valores involucrados en la teoría de la democracia, como la libertad y la igualdad no solo de formas sino de sustancia. De ahí surge la ciudadanía igualitaria, los ciudadanos iguales. El tema se complica por las obvias connotaciones que el término provoca frente al de ciudadanía y el de democracia. A pesar de que se trata de uno de los principios de la democracia, existe la dificultad creciente para tener una cabal comprensión de la misma, ya se hable de sus connotaciones éticas y como teoría normativa del orden social, así como de sus rasgos de justicia distributiva ${ }^{25}$.

Y la teoría de la democracia no es la excepción, ya que al considerar que como presupuesto categorial la igualdad está contenida en la democracia, no es difícil concluir con ese planteamiento: la democracia, como teoría social, exige igualdad en la toma de decisiones respecto a una problemática social que afecta a toda la comunidad o a gran parte de ella. Pero la toma de decisiones no es un factor aislado que se debe considerar en la práctica democrática cotidiana, sino que a priori se debe realizar un trabajo de discusión, crítica y análisis propositivo respecto al contenido de la problemática social a resolver, desde un punto de vista plural ${ }^{26}$ para que a partir de ahí los sujetos decisores puedan estar en las condiciones argumentativas y racionales de poder decidir. El producto de la deliberación no es otra cosa que una decisión razonada, analizada y revisada, que se traduce en la manifestación de una voluntad general, surgida directamente de las voluntades individuales, gracias a un mecanismo o instrumento de "recolección" y sistematización de esas voluntades:

24 Jürgen Habermas, Facticidad y validez. Sobre el derecho y el Estado democrático de derecho en términos de teoría del discurso, 374 (4ª ed., Trotta, Madrid, 2005).

25 Amartya Sen, Inequality Reexamined, 12 (Clarendon Press, Oxford, 1992).

26 Lo que conlleva, desde luego, una discusión de las diversas posturas que cada persona puede sostener y que va en proporción directa con su preconocimiento de la realidad social y democrática y con su experiencia personal respecto a su participación dentro del aparato estatal. A lo anterior se le ha llamado diversidad, en la cual se basan las nuevas posturas relativas a la tolerancia y a la posibilidad de expresar las ideas de forma libre, a pesar de no haber acuerdo sobre su contenido, sin mayor límite que los derechos ajenos. 
...la voluntad del pueblo significa, prácticamente, la voluntad de la porción más numerosa o más activa del pueblo; de la mayoría o de aquellos que logran hacerse aceptar como tal; el pueblo, por consiguiente, puede desear oprimir a una parte de sí mismo, y las precauciones son tan útiles contra esto como contra cualquier abuso de Poder (...) y en especulación politica se incluye ya la "tiranía de la mayoría" entre los males contra los cuales debe ponerse en guardia la sociedad ${ }^{27}$.

El concepto de mayoría supone un aspecto cuantitativo, interpretado por ciertos parámetros estatales para poder considerarlo como una decisión democrática, una determinación del mayor número de los integrantes de una sociedad. Por ello, la ley debe tener claridad en los procedimientos para otorgarles legitimidad a sus resultados, lo cual se traduce en una eficiencia de la función estatal y de las decisiones tomadas por el pueblo por medio de instrumentos de deliberación. La accesibilidad y la inteligibilidad de la ley es otro de los factores necesarios para lograr la deliberación de los miembros en una sociedad, ya que no es posible que se sigan los procedimientos o mecanismos de recolección de las voluntades si no se comprenden a cabalidad los mismos. Cuando la ley protege lo anterior y cuando garantiza también la adecuada aplicación de las normas fundamentales - llámese derechos humanos - está siendo acorde con una ideología democrática y lo que resta es hacerlo con una práctica de discusión, análisis y reflexión.

El ciudadano es el sujeto que realiza de manera individualizada la decisión, es el que integra y forma parte de una determinación colectiva. Así surge la pregunta: ¿para qué una democracia deliberativa? La respuesta surge de lo indispensable que es la discusión de las ideas, de las posturas y de las propuestas de carácter público; la premisa fundamental a lo anterior es el hecho de que las decisiones derivadas e interpretadas como voluntad general, afectan también a aquellos que no discutieron o a quienes no expresaron su voluntad o su decisión individualizada, e inciden sobre sus intereses a pesar de que el ciudadano no esté involucrado ${ }^{28}$ en ese ejercicio democrático. De ahí surge la importancia de deliberar, de la discusión

27 John Stuart Mill, Sobre la libertad, 59 (Alianza Editorial, Madrid, 1859, 2013).

28 Ya sea intencionalmente, es decir, por apatía, o porque se encuentra con obstáculos derivados de la falta de mecanismos administrados por las instituciones estatales o por la existencia ineficiente de los mismos; esto atiende, según quedó establecido, a la legitimidad de las instituciones. 
y la crítica incidentes en el propio beneficio o perjuicio de quienes forman parte de la sociedad. Alain Touraine señala que:

El sujeto integra identidad y técnicas, construyéndose como actor capaz de modificar su medio ambiente y de hacer de sus experiencias de vida pruebas de su libertad. [...]. En la medida que el sujeto se crea, el actor social está centrado en sí mismo y ya no en la sociedad; es definido por su libertad y ya no por sus roles. El sujeto es un principio moral en ruptura con la moral del deber que asocia la virtud con el cumplimiento de un rol social. El individuo se convierte en sujeto, no cuando se identifica con la voluntad general y cuando es el héroe de una comunidad, sino, al contrario, cuando se libera de las normas sociales del "deber de Estado"...29.

Desde el punto de vista de la democracia deliberativa, el sujeto es la evolución del individuo, es quien discute, cuestiona, razona, todo ello en escenarios públicos en los cuales puede hacerse oír y puede hacer llegar su voz y sus ideas a las mentes y las consciencias de los otros sujetos que forman parte de la sociedad. Es una amalgama que se genera entre el Estado y su componente humano; con una voz y razón suficientes para provocar cambios en la sociedad.

En este sentido, el sistema constitucional democrático no puede favorecer la concentración de la información política; restringir, limitar o acaparar tal información es una forma de afectar el ejercicio de las libertades públicas. Un estado constitucional de derecho debe incluir necesariamente determinados elementos estructurales que hagan posible el bienestar social, partiendo del imperio de la ley derivado de instituciones consolidadas que fusionen las necesidades del trinomio sociedad-estado-derecho. Lo anterior debe operar en virtud de la adecuada aplicación de la representatividad que dé legitimidad a los procesos políticos y que al final le dan forma a la estructura estatal y social.

\section{SUJETOS, ACTORES Y PROBLEMAS DE GOBERNANZA}

Frente a la pérdida de la confianza institucional, a la disminución de la democracia directa y la ausencia de mecanismos de participación

29 Alain Touraine, ¿Qué es la democracia?, 182-183 (Fondo de Cultura Económica, FCE, Ciudad de México, 2000). 
ciudadana, la debilitación del Estado constitucional en el caso de una sociedad expuesta a la inseguridad (como es el caso de México), resulta imperioso reorientar el papel de las instituciones que se han creado para lograr el desarrollo dentro de esquemas de gobernanza. Al hablar de gobernanza dentro del Estado constitucional, no podemos sino referirnos a los factores y actores que interactúan en el marco formal externo y en el marco formal interno. Nos referimos a estas dos arenas, porque dentro del Estado constitucional hay estructuras políticas, normativas y económicas formales e informales; al mismo tiempo, fuera del marco interno hay toda una arena de actores y factores de derecho, política y organismos económicos internacionales que constantemente influyen en la forma en que se articulan las decisiones para la gobernanza interna, en especial por la situación de inseguridad y erosión económica ${ }^{30}$.

Teóricamente, la gobernanza representa el medio de vida de una sociedad: "Se trata del ecosistema más amplio de la sociedad. Es el examen del papel de las instituciones, de los ciudadanos, la sociedad civil, normas y procesos que afectan la fijación del diseño de prioridades societarias" ${ }^{\prime 31}$. Aquí tenemos un concepto muy amplio que resalta la cualidad funcional de la gobernanza. Pero a su vez permite visualizar una fórmula horizontal del control del poder mediante el papel activo de los gobernados; en el que no es tan importante conocer quién gobierna sino para quién y cómo gobierna. Este pragmatismo de gobernanza no está relacionado con la mera tecnicidad de la decisión del gobierno, sino con la apertura, cuestionamiento y orientación la actividad del Estado hacia los intereses públicos.

La noción contemporánea de gobernanza se construye a partir de la relación fuerte entre gobierno y sociedad. Para José María Serna de la Garza, la gobernanza debe darse en función de los intereses

30 La inestabilidad económica mexicana se debe en buena parte a que las medidas financieras y hacendarias que vienen desde los años ochenta: "obligaron a efectuar reformas constitucionales, desregulaciones, privatizaciones, a usar instrumentos administrativos de mercado y a cancelar programas y organismos gubernamentales tan costosos como ineficientes, con la consecuencia de que el gobierno perdió poderes, capacidades, recursos y alcances, particularmente en el ámbito del crecimiento económico y del desarrollo social". Luis F. AguiLar, Gobernanza: el nuevo proceso de gobernar, 16 (Fundación Friedrich Naumann para la Libertad, México, 2010). Disponible en: http:// www.la.fnst.org/index.php/biblioteca-de-la-libertad/biblioteca-de-la-libertad-en-america-latina/ item/download/24_c4e2ee47bcbb24830a97e395eb340d2f

31 Cfr. Canada, Institute on Governance, IOG, Public Sector Governance. Disponible en: http://iog. ca/public-sector-governance/ 
públicos, tomando en cuenta la dimensión del Estado y la sociedad civil en la conducción de los asuntos públicos y la solución de los problemas $^{32}$. Luis F. Aguilar advierte que se trata de:

un nuevo proceso directivo, en tanto la definición y efectuación de los objetivos sociales es resultado de un nuevo tipo de relación entre gobierno y sociedad, que no es dominado por el gobierno y que, por ello, tampoco puede ser en modo de mando y control, dada la independencia política de los actores sociales y su fuerza relativa en virtud de los recursos que poseen y de los que el gobierno carece $^{33}$.

De este modo, la gobernanza es la unión de los sujetos Estadosociedad, en torno a las soluciones de los problemas comunitarios. Ambos sujetos son agentes activos de los procesos en los que se toman decisiones que implican la objetivación de los intereses comunes. Los factores e indicadores de la gobernanza intentan replantear el estudio de las relaciones del Estado y sus gobernados. No basta la existencia de reglas e instituciones en razón de que la importancia de gobernar mantiene una visión de efectividad, utilidad y de resolución de problemas. Además, como derecho subjetivo, se habla de la "buena gobernanza" con una acepción de exigencia individual ${ }^{34} \mathrm{y}$ con una visión objetiva que implica cierta disciplina de la administración pública ${ }^{35}$.

32 José María Serna de la Garza, Gobernanza, globalización y Estado: el caso de la Guardería ABC, en Formación y perspectivas del Estado en México, 389-414, 404-405 (HÉctor Fix-ZAMudio \& Diego VALAdÉs, coords., Instituto de Investigaciones Jurídicas, IIJ, Universidad Nacional Autónoma de México, UNAM, México, 2010). Disponible en: https://biblio.juridicas.unam.mx/bjv/detallelibro/2873-formacion-y-perspectivas-del-estado-en-mexico, https://archivos.juridicas.unam.mx/ www/bjv/libros/6/2873/20.pdf

33 Luis F. Aguilar, Gobernanza: el nuevo proceso de gobernar, 30 (Fundación Friedrich Naumann para la Libertad, México, 2010).

34 Por ejemplo, un enfoque normativo de este se halla en el artículo 41 de la Carta Europea de Derechos Fundamentales reconoce este derecho en los términos siguientes: "Derecho a una buena administración. 1. Toda persona tiene derecho a que las instituciones y órganos de la Unión traten sus asuntos imparcial y equitativamente y dentro de un plazo razonable". Parlamento Europeo, Consejo de la Unión Europea y Comisión Europea, Carta de los Derechos Fundamentales de la Unión Europea (2000/C 364/01), Proclamación solemne, Diario Oficial de las Comunidades Europeas, 18 de diciembre de 2000. Disponible en: http://www.europarl.europa.eu/charter/pdf/text_es.pdf

35 Para un estudio comprensivo de la construcción de este concepto, Lucio Pegoraro señala que la buena gobernanza no constituye ni una norma ni un principio pero que está relacionada con estos, y que: "a singole ulteriori concretizzazioni puntuali previste a vari livelli normativi o giurisprudenziali. Dove siano già contemplati, "sopra" e "sotto", principi e/o diritti che enuncino o disciplinino le strutture, i limiti, i fini, gli scopi della (per forza di cose "buona") amministrazione, enunciare un "diritto alla buona amministrazione" può configurare un mero esercizio verbale che si interpone con carica meramente emotiva e simbolica tra altre enunciazioni delle stesse situazioni giuridiche". Lucio Pegoraro, Esiste un "diritto" a una buona amministrazione? (Osservazioni critiche prelimi- 
La acepción novedosa entre la gobernanza y la forma de ejercer el poder es la conexión que se busca entre Estado y desarrollo (herramienta multidimensional permanente y activa para la búsqueda del bien común). Por su parte, Koldo Echebarría dice: "Si la gobernabilidad es simplemente la capacidad de un sistema político de resolver conflictos mediante reglas, la gobernabilidad democrática es aquella que lo hace a través de reglas democráticas, deseables en sí mismas como componentes indispensables del desarrollo humano"36.

En este marco se manifiesta la política del Estado constitucional. El bloque normativo de aspiraciones subjetivas y objetivas que contempla la Constitución es solo la piedra angular sobre la que se edifica la acción pública y privada para conseguir el desarrollo de la sociedad hacia los fines constitucionales. En este contexto, se añade el componente desarrollo humano que tiene por objeto que la acción política de los Estados siempre atienda el interés de los sujetos y grupos, en especial de los que en las condiciones actuales son más propensos a ser excluidos del desarrollo ${ }^{37}$.

La Organización de las Naciones Unidas ha promovido esta dinámica para detener la erosión del Estado constitucional y de las capacidades de los gobernados. De pronto, la necesidad de crear mejores condiciones de vida humana ha llevado a la conjunción de la economía, la ciencia política, el derecho y las humanidades en un mismo camino: el de la sociedad más igualitaria. Desde luego, esto implica una visión de conjunto de las ciencias mencionadas. Pero, sobre todo, implica la reorganización y coordinación de los

nari sull' (ab) uso della parola "diritto"), 5-6 Istituzioni del Federalismo: rivista di studi giuridici e politici, 543-565, 562 (2010). Disponible en: http://www.regione.emilia-romagna.it/affari_ist/ Rivista_5_6_2010/Pegoraro.pdf

36 Koldo ECHEBARRİA, Objetivar la gobernanza: funciones y metodología. Una aproximación a la objetivación del análisis institucional a través de indicadores de gobernabilidad (Ponencia presentada al IX Congreso Internacional del Centro Latinoamericano de Administración para el Desarrollo, CLAD, sobre la Reforma de Estado y de la Administración Pública, Madrid, 2-5, de noviembre de 2004). Disponible en: http://antigo.enap.gov.br/downloads/ec43ea4fObjetivarlagovernanza.pdf

37 El Informe de Desarrollo Humano de la ONU, en 2014 ya advierte la nueva concepción de las capacidades humanas: "Se requiere una atención especial en los periodos delicados: las inversiones en la educación infantil, la atención a las oportunidades de empleo para los jóvenes y el apoyo a las personas mayores son todos factores que mejoran las capacidades a lo largo del ciclo de vida". Organización de Naciones Unidas, ONU, Informe sobre Desarrollo Humano 2014, Sostener el Progreso Humano: Reducir vulnerabilidades y construir resiliencia, 4 (Programa de las Naciones Unidas para el Desarrollo, PNUD, Nueva York, 2014). Disponible en: http://www.undp.org/content/ dam/undp/library/corporate/HDR/2014HDR/HDR-2014-Spanish.pdf 
actores de la sociedad junto con un nuevo entendimiento del ambiente social, de sus agentes y cualidades. En el documento Beyond 2015: Media as Democracy and Development, la Organización de las Naciones Unidas para la Educación, Ciencia y Cultura (UNESCO) apunta varios postulados relativos a la inclusión democrática y la gobernanza para:

1. Que los ciudadanos conozcan su propio rol y se incluyan en los procesos de buen gobierno y el desarrollo sostenible.

2. Inculcar lealtad a los valores y procedimientos democráticos y por lo tanto cultivar cívica virtud (la participación, la solidaridad, la tolerancia, valor).

3. Adoptar individualmente las prácticas, rutinas, tradiciones asociadas con la ciudadanía democrática y los caminos del desarrollo sostenible.

4. Fomentar la construcción de los tipos de identidades plurales asociados con la ciudadanía democrática ${ }^{38}$.

Por lo tanto, la gobernanza, en esencia, significa la reorganización de la sociedad bajo criterios de racionalidad política, económica y jurídica en torno a valores comunes y con fines antropocéntricos. El concepto, sin embargo, tiene sus ventajas y desventajas. La amplitud de adjetivos que puede tener le da una apertura que podría debilitar su autonomía como sustantivo autónomo. Se afirma, en este sentido, que la gobernanza no tiene un marco concreto, o que su relación con la democracia y los derechos humanos no necesariamente está bien identificada (en particular cuando se comparan distintos lugares o tipos de democracia) ${ }^{39}$.

Pero más allá de lo que la teoría pueda o no identificar, la gobernanza es percibida como el éxito o el fracaso de la estructura de gobierno, de la administración pública. Al ciudadano común no podemos engañarlo:

38 United Nations Educational, Scientific and Cultural Organization, UNESCO, Beyond 2015: Media as Democracy and Development, 1-5 (Paris, 2013). Disponible en: http://www.unesco.org/new/ fileadmin/MULTIMEDIA/HQ/CI/CI/pdf/official_documents/beyond_2015_media_democracy_development.pdf

39 Organización de Naciones Unidas, ONU, What does Good Governance Mean? (September 2, 2012). Disponible en: http://unu.edu/publications/articles/what-does-good-governance-mean.html 
Situaciones de desorganización, negligencia en el trato, corrupción, discriminación, baja o imprevisible calidad del servicio, ineficiencia del desempeño... son todos factores que afectan negativamente la operación y los resultados de politicas, programas y servicios y acarrean costos a los ciudadanos usuarios, con el resultado final de una calificación desfavorable de la dirección del gobierno ${ }^{40}$.

Si intentamos evaluar la gestión de nuestro sistema de gobierno (en los tres niveles y en las tres funciones especializadas) con este parámetro (genérico), los resultados no son alentadores.

Por esta razón, surge la propuesta de crear mejores herramientas de diálogo entre gobierno y sociedad. Una reconstrucción de la relación mandatarios-mandantes. Por qué no decirlo: un pacto político distinto, definitivamente con pretensiones más amplias. Que no reduzca la democracia a su dimensión electoral; que la representación sea la verdadera legitimación en las decisiones parlamentarias; que la jurisdicción constitucional maximice sus efectos preventivos (antes que los represivos); y que los valores de la actividad administrativa (todo el entramado del poder ejecutivo) sean líneas de acción de las categorías constitucionales. Estas condiciones y cualidades son rasgos del Estado constitucional. El punto de quiebre es que las sociedades que forman parte del Estado no se sienten identificadas con estas condiciones. Por ende, es necesario reorientar la relación fuerte y la conexión de las normas constitucionales con un programa sociopolítico multidimensional de la cultura constitucional.

En cuanto a los sujetos de la gobernanza, podemos afirmar que la concepción clásica de "agentes de poder" no solo tiene rasgos plurales y horizontales, sino que se han mezclado al punto de que pueden escapar del control de una adecuada sistematización. En las sociedades modernas, el poder fragmentado del Estado no proviene solo de las instituciones legal y políticamente establecidas, que como grupo homogéneo comparte el reconocimiento (aunque no necesariamente la legitimación) oficial por medio de los canales habituales para ejercer el poder y tomar las decisiones mayoritarias. Sin embargo, otros grupos empresariales, de delincuencia nacional y transnacional, sectores locales inconformes y medios de comunicación constantemente influyen en este tipo de decisiones

40 Luis F. Aguilar, Gobernanza: el nuevo proceso de gobernar, 52 (Fundación Friedrich Naumann para la Libertad, México, 2010). 
y muestran que la percepción de un Estado, en buena medida, se nota en los titulares de los diarios ${ }^{41}$.

\section{A. Marco y factores internos}

\section{El marco interno de la gobernanza está compuesto por los poderes públicos, los medios de comunicación, la sociedad civil y los grupos que ejercen poder mediante el miedo, la violencia y el quebranta- miento de las normas jurídicas. En México, estos grupos irregulares pueden ser delincuentes habituales o grupos que operan dentro de la administración pública del gobierno federal, local ${ }^{42}$ o municipal. Del informe que rinde la Auditoría Superior de la Federación se desprenden irregularidades, desvío de recursos o malversación de fondos públicos ${ }^{43}$, que exhibe al poder legislativo como órgano polí- tico de una reputación no confiable y con tendencias a la corrupción.}

41 Por ejemplo, la visión externa de México es resumida por los medios internacionales de los epicentros del poder mundial. The Washington Post: Joshua Partlow \& Gabriela Martínez, Mexico's President Apologized for a Corruption Scandal. But the Nightmare goes on for the Reporter Who Uncovered it (The Washington Post, WorldViews, July 22, 2016). Disponible en: https://www.washingtonpost. $\mathrm{com} /$ news/worldviews/wp/2016/07/22/mexicos-president-apologized-for-a-corruption-scandal-butthe-nightmare-goes-on-for-the-reporter-who-uncovered-it/?utm_term=.4ae2d9274ea4. Financial Times: "Justice has collapsed in violent Mexican state, says rights group". JudE WeBBer, Murders ignored in Guerrero, says report (Financial Times, September 1, 2015). Disponible en: https://www. ft.com/content/aa7c5440-50da-11e5-b029-b9d50a74fd14. Der Spiegel: "Mass Abduction Reveals a Decaying Mexican State. Most murders don't even make the front page in Mexico anymore. But the recent abduction of 43 students has infuriated the country. The story has exposed the tight relationship between politics, law enforcement and organized crime. And it shows how weak the state has become". Der Spiegel Online, Teeth and Bones: Mass Abduction Reveals a Decaying Mexican State (Der Spiegel, 20 de noviembre de 2014). Disponible en: http://www.spiegel.de/international/ world/mass-abductions-in-mexico-reveal-a-decaying-state-a-1003836.html

42 En relación con el endeudamiento de las entidades federativas, la Auditoría Superior de la Federación afirma: "Los indicadores de sostenibilidad de las entidades agrupadas en el máximo nivel de riesgo probable muestran situaciones de elevado déficit primario, lo que implica limitaciones severas para generar recursos presupuestarios suficientes para atender el servicio de la deuda. También tienen un alto nivel de servicio de la deuda respecto a su gasto total e ingresos disponibles, en comparación con la media nacional de $2.8 \%$ y de $3.1 \%$, respectivamente". México, Cámara de Diputados, Auditoría Superior de la Federación, ASF, Análisis de la deuda pública de las entidades federativas y municipios, 114 (2012). Disponible en: http://www.asf.gob.mx/uploads/56_Informes_especiales_de_auditoria/1._Analisis_de_Deuda_Publica_Agosto_2012.pdf

43 Por ejemplo, la Cámara de Diputados: "Al solicitar la documentación justificativa y comprobatoria de la aplicación de los $\$ 1,166,674.7$ miles de pesos de Subvenciones... no se proporcionó la documentación que sustenta la aplicación de los recursos otorgados. Por lo tanto, no se contó con la información que permitiera evaluar la razonabilidad del gasto o comprobar si los recursos se ejercieron en trabajos legislativos, por lo que persiste una limitada rendición de cuentas en el ejercicio de los recursos por concepto de Subvenciones". México, Cámara de Diputados, Gestión Financiera, Informe del resultado de la fiscalización superior de la cuenta pública 2013. Auditoría financiera y de cumplimiento: 13-0-01100-02-0038, 5 (2013). Disponible en: http://www.asf.gob.mx/Trans/Informes/IR2013i/Documentos/Auditorias/2013_0038_a.pdf 
Por ello, el primer eslabón de la democracia es muy débil: los jugadores institucionales tienen un alto grado de incumplimiento con las normas mínimas de uso racional de los recursos públicos. Esto se convierte en una cultura popular de quebrantamiento de la ley, de la falta de liderazgo legislativo (como representantes ejemplares del pueblo) y de un déficit en la legitimación para tomar decisiones que representen al público, al grado de que sectores académicos han creado herramientas denominadas violómetro constitucional para sistematizar hechos y omisiones legislativas contrarias a la Constitución ${ }^{44}$.

Por su parte, el Poder Judicial Federal tampoco goza de una aceptación de respeto al imperio de la ley y no está exento de señalamientos de corrupción cuando se trata de casos especialmente complejos. Gabriel Ferreyra expone las fallas sistemáticas del poder judicial federal en su estudio sobre el Michoacanazo, en el que documenta la falta de certeza, la disparidad de la interpretación legal y los señalamientos de corrupción sistemática que comprende una red de nepotismo en el contexto legal y cultural de México; asimismo señala que este caso muestra el fiasco de la independencia judicial y del uso político de la ley penal, aunado al interés perseguido por las partes involucradas y a la búsqueda mediática de apoyo para las medidas políticas (en este caso, la lucha contra el narcotráfico) ${ }^{45}$.

Con este mensaje negativo que permea en la opinión pública, el poder judicial muestra su lado más débil a la hora de aplicar la Constitución como norma; que peligrosamente se sustituye por la "interpretación constitucional", lo que da pie a la volatilidad en la aplicación de la Ley con criterios restrictivos ${ }^{46}$.

44 La investigación de Roberto Duque-Roquero \& Juandiego Calero, del Centro de Investigación y Docencia Económicas, señala: "El Violómetro Constitucional es un instrumento digital que ofrece datos cronológicos y legislativos puntuales para medir, en tiempo real, las violaciones constitucionales en que incurre el Congreso de la Unión al no cumplir con sus obligaciones legislativas dentro de los plazos establecidos en la ley". Roberto Duque-Roquero \& Juandiego Calero, Violómetro Constitucional, instrumento digital (Centro de Investigación y Docencia Económicas, CIDE, Maestría en Periodismo y Asuntos Públicos del CIDE, Fundación Omidyar Network, México, s.f.). Disponible en: http://periodismocide.org/eventos/violometro/

45 Gabriel Ferreyra, The Michoacanazo: A Case-Study of Wrongdoing in the Mexican Federal Judiciary, VIII Mexican Law Review, 1, 3-31 (2015). Disponible en: http://ac.els-cdn.com/ S1870057815000025/1-s2.0-S1870057815000025-main.pdf?_tid=72e7cf04-ea6d-11e6-bb6800000 aacb35f\&acdnat $=1486166828 \_4 c 440 \mathrm{c} 2703681 \mathrm{a} 745 \mathrm{e} 6 \mathrm{bc} 2 \overline{8} \mathrm{a} 436 \mathrm{ef} 1 \mathrm{a} 0$

46 Nos referimos a las restricciones constitucionales que se han impuesto a la interpretación favorable de los derechos humanos, que entre otros menciona que el control de convencionalidad: “[...] solo conlleva a que si en los instrumentos internacionales existe una protección más benéfica para 
En cuanto a todos los operadores de seguridad y de la administración pública, las deficiencias son notoriamente peligrosas y lo preocupante es el nulo avance sobre este tema, que desde 2006 es el lastre de los gobiernos. Uno de los casos más representativos es de los estudiantes de Ayotzinapa ${ }^{47}$. Este caso representa el incumplimiento sistemático de las obligaciones convencionales — garantía de no repetición y efecto útil de los tratados-impuestas por la Corte Interamericana de Derechos Humanos ${ }^{48}$.

Por otra parte, según John Bailey, la incidencia de los grupos de narcotráfico en la gobernanza democrática es un factor medular en el desarrollo de México ${ }^{49}$. Su análisis lleva a que la intensidad del crimen aumenta la fragmentación democrática y de la seguridad del Estado. El poder de los grupos de narcotráfico es local, regional, nacional y transnacional, lo que dificulta su control y sometimiento $^{50}$. El profesor de Berkeley advierte que la organización y el tráfico de drogas influyen en múltiples dimensiones en la forma del

la persona respecto de la institución jurídica analizada, esta se aplique, sin que tal circunstancia signifique que, al ejercer tal función jurisdiccional, dejen de observarse los diversos principios constitucionales y legales - legalidad, igualdad, seguridad jurídica, debido proceso, acceso efectivo a la justicia, cosa juzgada_-, o las restricciones que prevé la norma fundamental, ya que de hacerlo, se provocaría un estado de incertidumbre en los destinatarios de tal función". Suprema Corte de Justicia de la Nación, Segunda Sala, Jurisprudencia 56/2014 (10a.), 30 de abril de 2014, Gaceta del Semanario Judicial de la Federación, 772, Libro VI, 23 de mayo de 2014. Disponible en: http://sjf. scjn.gob.mx/sjfsist/Paginas/wfDetalleTesis.aspx?SN=1\&Clase=DetalleTesisBL\&ID=2006485\&Ex presion=Jurisprudencia $\% 2056 / 2014 \% 2010$ a. Sobre este punto, infra, se anotan otros casos y crítica más amplia en referencias de nota 64.

47 La inseguridad pública, el uso de la fuerza y el distanciamiento de los parámetros racionales de investigación son algunos de los factores más comunes expuestos en el informe que los expertos de Comisión Interamericana de Derechos Humanos detectaron en este caso. Este informe toca nuevamente la exigencia a todas las autoridades públicas que están en la obligación de intervenir para prevenir una posible violación de derechos humanos; desmilitarizar las estrategias de seguridad en el país; el plan de retiro de las fuerzas militares de las operaciones de seguridad pública, implementando los mecanismos necesarios para que cuerpos policiales profesionales, civiles y democráticos, de carrera y especializados, asuman esta función. Comisión Interamericana de Derechos Humanos, CIDH, Informe de Grupo Interdisciplinario de Expertos Independientes, GIEI, convocado por la Comisión Interamericana de Derechos Humanos, 358 y 359 (México, 2015). Disponible en: http:// www.oas.org/es/cidh/actividades/giei/GIEI-InformeAyotzinapa1.pdf, http://www.oas.org/es/cidh/ actividades/giei/GIEI-InformeAyotzinapa2.pdf, http://www.oas.org/es/cidh/actividades/giei.asp

48 En especial del caso Radilla-Pacheco vs. México, en el que da cuenta de la violación sistemática de la seguridad comunitaria y la falta de protección estatal para las habitantes de la Sierra de Guerrero, así como de los abusos que sufren por grupos estatales de poder, paramilitares y narcotraficantes. Corte Interamericana de Derechos Humanos, CorteIDH, Caso Rosendo Radilla-Pacheco vs. México, Serie C 209, Fondo, reparaciones y costas, sentencia de 23 de noviembre de 2009. Disponible en: http://www.corteidh.or.cr/docs/casos/articulos/seriec_209_esp.pdf. Comisión Nacional de los Derechos Humanos, CNDH, Informe Especial Sobre los Grupos de Autodefensa y la Seguridad Pública en el Estado de Guerrero (México, 2008).

49 John Bailey, Crimen e impunidad. Las trampas de la seguridad en México, 82-92 (Debate, México, 2014).

50 John Bailey, Crimen e impunidad. Las trampas de la seguridad en México, 167-172 (Debate, México, 2014). 
ejercicio de la organización administrativa y política, en la corrupción policiaca, en la intimidación a los funcionarios, la inyección de dinero en las campañas políticas, y que incluso ha permeado la económica informal por medio de las redes de contrabando y control de mercancía ilícita en las calles ${ }^{51}$.

Con este panorama, el papel del narcotráfico no solo como factor de ilicitud sino como barrera para la gobernanza, es imposible que las soluciones que se esbozan sobre el problema de la seguridad y el narcotráfico sean por la única vía de la política criminal. Las fugas de Joaquín Guzmán Loera, Chapo Guzmán, mostraron la erosión del sistema de seguridad pública y de la política interior de seguridad. La fuga de un penal de "máxima seguridad" el 11 de julio de 2015 muestra los graves problemas de corrupción que existen en el sistema nacional de seguridad y la falla sistemática del sistema de prisiones y de restricción de libertad ${ }^{52}$. En este contexto, la seguridad pública es percibida como un sector contrario a los intereses de la ciudadanía, debido a la constante participación de agentes de seguridad en actividades delictivas que tergiversan la seguridad para "cuadrar delitos"

Los indicadores descritos exponen la fragilidad constitucional de la gobernanza interna. Como si se tratara de problemas y soluciones separadas, las reformas constitucionales de los últimos años no

51 John Bailey, Crimen e impunidad. Las trampas de la seguridad en México, 182-185 (Debate, México, 2014).

52 Con un estudio empírico reciente y con datos de campo sobre las condiciones que imperan en las prisiones del país, el relator de la ONU afirma dos puntos que sitúan este problema en las antípodas: 1. Que no se ha aplicado ni medianamente el modelo de reinserción social propuesto en las reformas de derechos humanos de 2008 (nuevo sistema penal) y 2011. 2. Que hay una tendencia de la política criminal de aumentar los niveles de encarcelamiento como única solución a los problemas de seguridad ciudadana y que se han incrementado los niveles de tortura, violencia, homicidios, hacinamiento y sobrepoblación del sistema penitenciario, lo que impacta en la vida de las personas privadas de libertad. El informe pone énfasis en la ausencia de mecanismos de control para mejorar las situaciones degradantes de las prisiones mexicanas, que dicho sea de paso, después de Estados Unidos y Brasil, es el tercer país que cuenta con más personas privadas de su libertad. JuAN E. MÉNDEZ, Informe del Relator Especial sobre la tortura y otros tratos o penas crueles, inhumanos o degradantes. Adición Misión a México (2015). Disponible en: http://www.acnur.org/t3/fileadmin/ Documentos/BDL/2015/9930.pdf?view=1

53 Es decir, crear condiciones ficticias de criminalidad. Sobre la participación delictiva de los policías se dice que son víctimas propiciatorias para la opinión pública sobre las cuales actores centrales del Estado escenifican una reinvención de su propia legitimidad; personajes de una trama orquestada para otorgar precarias prórrogas de conformidad social a unas instituciones que son percibidas como construidas contra y a pesar de los ciudadanos. Miguel A. Ruiz-Torres \& Elena AzaolaGarrido, Cuadrar el delito. Corrupción institucional y participación de policías en el secuestro en México, 22 Perfiles Latinoamericanos, 44, 91-112 (2014). Disponible en: http://www.flacso.edu. $\mathrm{mx} /$ publicaciones/revista_perfiles/Cuadrar-el-delito-Corrupcion-institucional-y-participacion-de 
han permeado la cultura constitucional local y solo han quedado en letra muerta ${ }^{54}$. Esto sirve de muestra para separar el tema del discurso normativo oficial de los poderes públicos con la realidad que la mayoría de los mexicanos vive. Uribe y De Paz afirman:

[...] the emptiness of the "structural reforms" that have been lodged for more than thirty years in Mexico without any positive transformation of the state and its functions. Therefore, the simplicity of Constitutional reforms without an axis considering the Constitutional objectives as public goods [...] cannot prosper and remain in the linguistic dimension without zero influence on reality ${ }^{55}$.

En este marco, a contracorriente, la realidad rebasa la dinámica del discurso constitucional y crea una narrativa que atenta contra esas normas dispuestas para gobernar. A pesar de ello, el trabajo de los sectores académicos y de la sociedad civil sigue proponiendo mecanismos de gobernanza más incluyente. Nuevas formas de dar viabilidad a las normas constitucionales mediante la participación activa de la sociedad civil por medio de la gestión de mejoras en la administración de justicia, el establecimiento del litigio estratégico en temas sociales importantes para empoderar a la población (casos del derecho al agua, derechos a la educación, derechos indígenas ${ }^{56}$.

\section{B. Marco y factores externos}

El marco internacional de la gobernanza ha influido negativamente en las finanzas mexicanas. México no ha sabido aprovechar su posición estratégica con sus vecinos del norte, ya que los gobier-

54 Se trata de diversas reformas constitucionales fallidas, que desde hace diez años se han implementado con la intención de modernizar, democratizar y fortalecer México. Desde 2006, la reforma política se planteó para evitar la volatilidad política y tuvo por objetivo crear nuevos mecanismos electorales y administrativos para los partidos políticos (2007); la laboral se hizo para crear nuevos empleos, en realidad empeoró el sector formal (2012); la energética mejoraría los recursos y el gasto de la nación (diciembre 2013); otra reforma de papel fue la que creó el sistema anticorrupción (2015 y leyes reglamentarias de 2016). Todas ellas, comparadas con la realidad no reflejan ningún avance.

55 Enrique Uribe-Arzate \& IsaAc de Paz-González, The Constitutional Permeability Principle: Guidelines towards a Constructive Constitutional Theory in Mexico, 5 International Journal of Humanities and Social Science, IJHSS, 6, 21-27 (2015). Disponible en: http://www.ijhssnet.com/ journals/Vol_5_No_6_June_2015/3.pdf

56 La lucha de estos pueblos por conservar sus recursos frente a la intrusión del Estado y de las empresas globales se aborda dentro del contexto supranacional y local de los derechos socioeconómicos en México: IsaAc de Paz-GonzÁlez, Constitucionalismo y justiciabilidad de los derechos sociales. Estudio comparado internacional y Leading Cases a través del juicio de amparo en México, especialmente 456-467 (Biblioteca Porrúa de Derecho Procesal Constitucional, Instituto Mexicano de Derecho Procesal Constitucional, México, 2016). 
nos han decidido subordinar el mercado interno a las presiones financieras globales. La reciente caída de los precios del petróleo y la volatilidad del peso mexicano muestran la falta de acuerdos convincentes de que la política exterior mexicana tiene una meta clara en la relación con el norte del continente. La riqueza económica de México ha sido poco aprovechada, aunada al mensaje negativo que envía el poder ejecutivo debido a los múltiples casos de corrupción en que el presidente y su gabinete se han visto involucrados.

En este marco internacional, México no muestra señales contundentes de dirección política y económica. Las cifras de los últimos 30 años dan cuenta de un mercado interno débil ${ }^{57}$ y la escalada del dólar desde el verano de 2016, junto con la deuda pública son datos alarmantes ${ }^{58}$. Esto necesariamente aumenta el desempleo, la pobreza y - por ende, aumenta - la delincuencia ${ }^{59}$.

Como se puede analizar, esta serie de factores excluyentes de la buena gobernanza constituyen una sola barrera que detiene el progreso de todos los sectores: del gobierno, de la sociedad y de los agentes comerciales. El clima de desconfianza que generan las circunstancias - mencionadas líneas arriba- complica que Mé-

57 Un estudio comparado del crecimiento económico desde 1981 a 2011 explica el comportamiento de las variables del poco crecimiento de la economía nacional y concluye que: "un mayor y eficaz apoyo del gobierno a las empresas nacionales podría incrementar el nivel de modernización y productividad de estas empresas, y llevar así a una reducción sistémica de precios internos, y con ello, a un tipo de cambio competitivo necesario para competir en la economía global". FRANCISCO Martínez, Luis Quintana \& Rafael Valencia, Análisis macroeconómico de los efectos de la liberalización financiera y comercial sobre el crecimiento económico de México, 1988-2011, 23 Perfiles Latinoamericanos, 45, 79-104 (2015). Disponible en: http://www.flacso.edu.mx/publicaciones/ revista_perfiles/Analisis-macroeconomico-de-los-efectos-de-la-liberalizacion

58 Desde 2012 a 2016, el peso mexicano se ha devaluado 40\%. Tres billones de pesos es el monto de la deuda pública. Una columna especializada en análisis económico sintetiza la cruda realidad mexicana: "A pesar del vertiginoso aumento de la deuda, México no crece económicamente ni en lo social su población reporta mejoría (no hay desarrollo, pues), y año tras año se encojen [sic] los presupuestos para educación, salud, ciencia y tecnología y demás renglones prioritarios para la nación, mientras avanza incontenible el destinado a cubrir el costo financiero de la deuda pública". Carlos Fernández-Vega, México SA, Deuda oprime presupuesto, Costo se multiplicó por 13, Cordero, Meade, Videgaray. El Delfín (12 de septiembre de 2016). Disponible en: http://eldelfin2020. blogspot.com.co/2016/09/mexico-sa 12.html

59 El Banco Mundial en 2012 alertaba: "Por estos motivos, prevenir la violencia juvenil requiere programas específicos y políticas enfocadas en los jóvenes y las vulnerabilidades que enfrentan. Aumentar la participación de los jóvenes en las decisiones [...] es fundamental para la efectividad de la política de prevención del delito". Banco Mundial, La violencia juvenil en México: Reporte de la situación, el marco legal y los programas gubernamentales (2012). Disponible en: http:// documentos.bancomundial.org/curated/es/277681468155375869/La-violencia-juvenil-en-Mexicoreporte-de-la-situacion-el-marco-legal-y-los-programas-gubernamentales 
xico salga a corto plazo de la crisis de seguridad, económica y de gobernabilidad.

En esta lógica, el derecho constitucional y las disposiciones convencionales no pueden convertirse en instrumentos estáticos. No se trata de un problema de ausencia de normas, sino de aplicación y vigencia con resultados palpables de la Constitución y de todo el marco de tratados que tenemos firmados. La norma constitucional tendrá el efecto que se le quiera dar siempre y cuando su rigurosa defensa comience con el cumplimiento de sus postulados; más mecanismos preventivos y de eficacia al programa político que mecanismos represivos, con esto se daría a la cultura constitucional un plano multidimensional.

No olvidemos que dentro del poder legislativo opera la primera forma de regularidad constitucional. La elaboración de leyes y la ejecución de las facultades amplias que tienen los congresos locales para mejorar y armonizar su trabajo con las Cámaras de Diputados y Senadores de la Federación, son dos aspectos que no se han explotado como debe ser para entablar los diálogos constitucionales necesarios para el trabajo legislativo, pues con ello aumenta la deliberación de los representantes populares y la disertación de las ideas de acuerdo a las necesidades de cada entidad sin salirse del marco federal.

Por su parte, la Suprema Corte de Justicia de la Nación ha hecho un papel medianamente progresista, debido a una decisión regresiva sobre la eficacia de los tratados internacionales y de los límites a los derechos humanos, que se trazaron en la Contradicción de tesis 293/2011, en la que se retoma el concepto de jerarquía normativa frente a la jerarquía del contenido esencial de los derechos humanos ${ }^{60}$.

60 Para una crítica muy puntual sobre este tema, se recomienda la obra de Fernando Silva-García, Principio Pro Homine vs. restricciones constitucionales. ¿Es posible constitucionalizar el autoritarismo? (Biblioteca Porrúa de Derecho Procesal Constitucional, México, 2014). Suprema Corte de Justicia de la Nación, Pleno, Contradicción de tesis 293/2011, Resolución del 3 de septiembre de 2013. Disponible en: http:/www2.scjn.gob.mx/asuntosrelevantes/pagina/seguimientoasuntosrelevantespub.aspx $? \mathrm{id}=129659$ \&seguimientoid $=556$ 


\section{Gobernanza posnacional}

La estabilidad económica, sin duda, está entre los factores supranacionales que influyen en un Estado constitucional. Los institutos financieros internacionales ven en México un país con potencial para el desarrollo de productividad. El marco internacional tiene su mira puesta sobre México en particular por la crisis de derechos humanos. La incorporación a la Organización de Estados Americanos, OEA, por medio de sus órganos de derechos humanos (Corte y Comisión Interamericana), es una plataforma de gobernanza que no podemos pasar por alto. La jurisdicción internacional no resolverá los problemas nacionales, pero puede contribuir positivamente, solo si tenemos un poder judicial eficiente e independiente que garantice el cumplimiento de las normas nacionales e internacionales ${ }^{61}$ bajo la imperatividad de la Constitución y del derecho internacional de los derechos humanos. La gobernanza más allá de la nación refleja el grado de compromiso de México con las soluciones que plantean los órganos supranacionales. El fortalecimiento de las decisiones de la Corte Interamericana de Derechos Humanos y su adaptación en la normativa interior (tanto como adopción de medidas cautelares de la Comisión Interamericana) son una plataforma de nuevos procesos para la elaboración de políticas públicas conforme lo ordenan los resolutivos de las sentencias interamericanas dictadas en contra de México ${ }^{62}$.

61 Una explicación más extensa al respecto es proporcionada por AlejandRa Flores-MartínEz \& ENRIQUE URIBE-ARZATE, La superación del monopolio proteccionista de los derechos humanos en el estado constitucional mexicano, a partir de la reforma al articulo primero constitucional, 129 Vniversitas, 103-134 (2014). Disponible en: http://revistas.javeriana.edu.co/index.php/vnijuri/article/ viewFile/11947/9782

62 En especial: Corte Interamericana de Derechos Humanos, CorteIDH, Caso González y otras (Campo Algodonero) vs. México, Serie C 205, Fondo, reparaciones y costas, sentencia de 16 de noviembre de 2009. Disponible en: http://www.corteidh.or.cr/docs/casos/articulos/seriec_205_esp.pdf. Corte Interamericana de Derechos Humanos, CorteIDH, Caso Rosendo Radilla-Pachéco vs. México, Serie C 209, Excepciones preliminares, fondo, reparaciones y costas, sentencia de 23 de noviembre de 2009. Disponible en: http://www.corteidh.or.cr/docs/casos/articulos/seriec_209_esp.pdf. Corte Interamericana de Derechos Humanos, CorteIDH, Caso Fernández-Ortega vs. México, Serie C 215, Fondo, reparaciones y costas, sentencia de 30 de agosto de 2010. Disponible en: http://www. corteidh.or.cr/docs/casos/articulos/seriec_215_esp.pdf. Corte Interamericana de Derechos Humanos, CorteIDH, Caso Valentina Rosendo Cantú vs. México, Serie C 216, Excepción preliminar, fondo, reparaciones y costas, sentencia de 31 de agosto de 2010. Disponible en: http://www.corteidh.or.cr/ docs/casos/articulos/seriec_216_esp.pdf. Corte Interamericana de Derechos Humanos, CorteIDH, Caso Teodoro Cabrera-García y Rodolfo Montiel-Flores vs. México, Serie C 220, Excepción preliminar, fondo, reparaciones y costas, sentencia de 26 de noviembre de 2010. Disponible en: http:// www.corteidh.or.cr/docs/casos/articulos/seriec_220_esp.pdf 


\section{POLÍticas PÚBlicas: Democratización DE LA GOBERNANZA}

En el contexto problemático del Estado constitucional mexicano, ¿qué podemos plantear para fortalecer un programa nacional de política constitucional? En respuesta a los problemas nacionales, en el comienzo de la joven república mexicana, a principios del siglo XX Andrés Molina Enríquez escribió Los grandes problemas nacionales $^{63}$. El momento constitucional que vivimos no es para menos. El programa normativo de la Constitución no puede quedar en la indemnidad del texto. Un nuevo patriotismo constitucional (a la manera de la Ley fundamental de Bonn, que permitió la reconstrucción de la Alemania de la posguerra) debe erigirse dentro de este caos de seguridad, de inestabilidad económica y crisis de derechos humanos.

La planeación coordinada y orientada hacia cada contexto local puede hacer la diferencia entre un país próspero y un fracaso del Estado, si seguimos aplicando medidas disuasivas bajo la lupa de la militarización y el uso político de la justicia penal ${ }^{64}$. Lo que vimos en los casos Michoacanazo, Ayotzinapa (y otros como Tlatlaya ${ }^{65}$, aunado a la debilidad de la economía nacional) no es más que un síntoma de la desintegración de una clase política incapaz de mantener un nivel racional de la ejecución de las normas constitucionales. Un ejercicio político coordinado de las previsiones de la Constitución implica la planeación con objetivos — a corto y me-

63 Andrés Molina-Enríquez, Los grandes problemas nacionales (Imprenta de A. Carranza e Hijos, México, 1909). Disponible en: http://www.biblioteca.org.ar/libros/155877.pdf, http://www.cervantesvirtual.com/obra/los-grandes-problemas-nacionales--0/

64 Nos referimos a la figura jurídica del arraigo como medida para combatir opositores políticos. Según algunos datos empíricos, el $96 \%$ de los casos en arraigo ha fracasado. Sobre este punto, es posible consultar: México, Cámara de Diputados, LXI Legislatura, Arraigo judicial: datos generales, contexto y temas de debate, Carpeta de indicadores y tendencias sociales número 13 (México, noviembre de 2011). Disponible en: http://www3.diputados.gob.mx/camara/content/download/269265/825108/ file/Carpeta13_Arraigo_judicial.pdf

65 Todos ellos han suscitado intervención de la Comisión Interamericana de Derecho Humanos por medio de medidas cautelares: Comisión Interamericana de Derechos Humanos, CIDH, Caso Clara Gómez González y otros vs. México, Medidas cautelares, MC 423/14, 10 de octubre de 2014. Disponible en: https://www.oas.org/es/cidh/decisiones/pdf/2014/MC423-14-ES.pdf. Comisión Interamericana de Derechos Humanos, CIDH, Caso Estudiantes de la Escuela Rural Raúl Isidro Burgos vs. México, Medidas cautelares, MC 409/14, 3 de octubre de 2014. Disponible en: http://www.oas.org/ es/cidh/decisiones/pdf/2014/MC409-14-ES.pdf. Comisión Interamericana de Derechos Humanos, CIDH, Caso Margarita Marin-Yan y otros vs. México, Medidas cautelares, MC 29/16, 15 de abril de 2016. Disponible en: https://www.oas.org/es/cidh/decisiones/pdf/2016/MC29-16-Es.pdf 
diano plazo - que puedan ser medibles, modificados, suprimidos o repetidos, dependiendo de su éxito o fracaso.

La gobernanza que plantea el uso racional de las decisiones públicas no puede estar alejada de una metodología identificable que busque cumplir objetivos específicos en todos los sectores de la planeación política. Como parte de la buena gobernanza — abierta y democrática-, la Constitución facilita la deliberación pública por medio de los órganos autónomos que tienen un valor societario que puede ser articulado como un canal permanente para la revisión y modulación de los planes de trascendencia constitucional ${ }^{66}$.

Por otro lado, de acuerdo con Daniel Eduardo Bonilla-Maldonado, no debe perderse de vista que la fragmentación del poder facilita su control y limita su abuso, pues la concentración de este conlleva los riesgos del autoritarismo; y advierte sobre este punto que el liberalismo aspira a "que el diseño y la transformación racional continua de las tres ramas del poder público logren controlar la imaginación corrupta que inventará perpetuamente formas de eludir las fronteras institucionales que la limitan"67.

Muchas de las contiendas constitucionales son producto de la ausencia de acuerdos y mecanismos de inclusión de las decisiones públicas. En este caso, proponemos que cada órgano constitucional autónomo sea el portavoz de la sociedad (sin perjuicio de los típicamente conocidos). Las políticas públicas participativas están ligadas a la democracia de las decisiones del poder. No es necesario agotar las instancias judiciales para decir que se logró el respeto a la Constitución. Es necesaria, por consiguiente, una lectura de la Constitución en clave dialógica, política y emancipatoria.

Finalmente, la seguridad humana - como categoría inserta en el Estado Constitucional de Derecho - es una de las metas a lograr mediante las políticas públicas que emanen del mismo; aunado a esto, el ingrediente de la democratización en el diseño de estas políticas es un factor imprescindible para lograr también la buena

66 Señalamos que se trata de temas por lo demás importantes, porque cada uno tiene qué ver con las funciones sociales que la Constitución asigna para el ejercicio del poder. El trato que hasta ahora tienen los organismos constitucionales autónomos es de adorno institucional de la democracia electoral. Si los tomamos un poco más en serio, podríamos construir órganos que dialoguen con los sectores social, académico, político y económico de forma abierta y propositiva.

67 Daniel Eduardo Bonilla-Maldonado, La arquitectura conceptual del principio de separación de poderes, 131 Vniversitas, 231-276 (2015). Disponible en: http://revistas.javeriana.edu.co/index.php/ vnijuri/article/view/15028/12491 
gobernanza, la cual constituye, en última instancia, el gran objetivo de la seguridad humana, en la cual se puede identificar - entre otras - la dimensión relativa a la seguridad comunitaria (con su respectiva conexión con el tema de la resiliencia), ya que constituye uno de los elementos que están específicamente anclados en los fenómenos de la realidad social. 


\section{CONCLUSIONES}

Primera. Se ha considerado la existencia de una falla sustancial en las funciones del ente estatal, por lo que, en el diseño de las políticas públicas, recomendamos cumplir los siguientes factores: a) evitar la tiranía, b) establecer derechos esenciales, c) garantizar la libertad general, d) procurar la autodeterminación y contribuir al desarrollo humano; con ello, la función y relación Estado-sociedad podrá verificar una reestructuración desde los parámetros de la democracia deliberativa y así reforzar las políticas públicas.

Segunda. Para abordar el aspecto democrático en un Estado constitucional en términos de gobernanza y de las políticas públicas, recomendamos hacerlo desde el aspecto deliberativo que la propia teoría de la democracia contiene en sus postulados, ya que la deliberación pública legitima las decisiones adoptadas por la ciudadanía como producto de la discusión racional, imparcial y abierta; lo anterior debe estar basado en la diversidad de razonamientos individuales que fusionados mutan en una homogeneización decisional ciudadana.

Tercera. La noción contemporánea de la gobernanza se construye a partir de una robusta relación entre gobierno y sociedad, ya que une al gobierno con la sociedad en torno a las soluciones de los problemas del espacio público y, sobre todo, en los procesos decisorios y deliberativos de los intereses comunes, lo que resalta la importancia de gobernar útil y efectivamente; por ello, recomendamos que en el diseño de las políticas públicas se tenga en cuenta que la gobernanza es la reorganización de la sociedad bajo criterios de racionalidad política, económica y jurídica en torno a valores comunes y con fines antropocéntricos.

Cuarta. Para lograr una gobernanza basada en las decisiones públicas, y estas a su vez en las discusiones democrático-deliberativas, que racionalicen el producto decisional bajo una metodología concreta coadyuvante del cumplimiento de objetivos gubernamentales, recomendamos que sea proyectada por medio de políticas públicas discutidas por la ciudadanía, fundamentadas en los preceptos constitucionales y procesadas adecuadamente en los elementos adjetivos institucionales y estatales. 


\section{BIBLIOGRAFÍA}

\section{Libros}

Aguilar, Luis F., Gobernanza: el nuevo proceso de gobernar (Fundación Friedrich Naumann para la Libertad, México, 2010). Disponible en: http://www.la.fnst. org/index.php/biblioteca-de-la-libertad/biblioteca-de-la-libertad-en-americalatina/item/download/24_c4e2ee47bcbb24830a97e395eb340d2f.

Bailey, John, Crimen e impunidad. Las trampas de la seguridad en México (Debate, México, 2014).

Burdeau, Georges, Écrits de Droit constitutionnel et de Science politique, Textes réunis et préfacés par Jean Marie Denquin (Charles Leben, dir., Éditions Panthéon Assas, Collection Les introuvables, Paris, 2011).

Díaz, Elías, Estado de Derecho y sociedad democrática (Taurus, Madrid, 1966).

Habermas, Jürgen, Facticidad y validez. Sobre el derecho y el Estado democrático de derecho en términos de teoría del discurso (4a ed., Trotta, Madrid, 2005).

Mill, John Stuart, Sobre la libertad (Alianza Editorial, Madrid, 1859, 2013).

Molina-Enríquez, Andrés, Los grandes problemas nacionales (Imprenta de A. Carranza e Hijos, México, 1909). Disponible en: http://www.biblioteca.org. ar/libros/155877.pdf, http://www.cervantesvirtual.com/obra/los-grandesproblemas-nacionales--0/

Paz-GonzÁlez, IsAaC De, Constitucionalismo y justiciabilidad de los derechos sociales. Estudio comparado internacional y Leading Cases a través del juicio de amparo en México (Biblioteca Porrúa de Derecho Procesal Constitucional, Instituto Mexicano de Derecho Procesal Constitucional, México, 2016).

Sen, Amartya, Inequality Reexamined (Clarendon Press, Oxford, 1992).

Silva-García, Fernando, Principio Pro Homine vs. Restricciones constitucionales ¿Es posible constitucionalizar el autoritarismo? (Biblioteca Porrúa de Derecho Procesal Constitucional, México, 2014).

Touraine, Alain, ¿Qué es la democracia? (Fondo de Cultura Económica, FCE, Ciudad de México, 2000).

\section{Contribución en obras colectivas}

Flores-Mendoza, Imer Benjamín, Law, Liberty and the Rule of Law (in a Constitutional Democracy), en Law, Liberty, and The Rule of Law, 77-101 (IMER BeNJAmín Flores-Mendoza \& Kenneth Einar Himma, eds., Springer Science+Business Media, Dordrecht, Netherlands, 2013).

Paz-González, Isaac de \& Garita-Alonso, Arturo, Discusión democrática: nuevos derroteros en el Parlamento mexicano, en El derecho parlamentario mexicano. Una visión de actualidad (EnRique Uribe-Arzate \& JoAquín Ordóñez-Sedeño, AM Editores y Universidad Autónoma del Estado de México, México, 2015). Disponible en: https://www.academia.edu/15126416/Discusi $\%$ C3\%B3n_ 
democr $\%$ C3\%A1tica_nuevos_derroteros_en_el_Parlamento_mexicano

Serna de la Garza, José María, Gobernanza, globalización y Estado: el caso de la Guardería ABC, en Formación y perspectivas del Estado en México, 389-414 (Héctor Fix-Zamudio \& Diego Valadés, coords., Instituto de Investigaciones Jurídicas, IIJ, Universidad Nacional Autónoma de México, UNAM, México, 2010). Disponible en: https://biblio.juridicas.unam.mx/bjv/detalle-libro/2873formacion-y-perspectivas-del-estado-en-mexico, https://archivos.juridicas. unam.mx/www/bjv/libros/6/2873/20.pdf

\section{Revistas}

Besselink, M. F. Leonard, National and Constitutional Identity before and after Lisbon, 6 Utrecht Law Review, 3, 36-49 (2010). Disponible en: https://www. utrechtlawreview.org/articles/abstract/10.18352/ulr.139/

Bogdandy, Armin von, Ius Constitutionale Commune en América Latina: una mirada a un constitucionalismo transformador, 34 Revista Derecho del Estado, 3-50 (2015). Disponible en: http://revistas.uexternado.edu.co/index.php/derest/article/ view/4198/4643

Bonilla-Maldonado, Daniel Eduardo, La arquitectura conceptual del principio de separación de poderes, 131 Vniversitas, 231-276 (2015). Disponible en: http:// revistas.javeriana.edu.co/index.php/vnijuri/article/view/15028/12491

Fernández-Vega, Carlos, México SA, Deuda oprime presupuesto, Costo se multiplicó por 13, Cordero, Meade, Videgaray, El Delfín (12 de septiembre de 2016). Disponible en: http://eldelfin2020.blogspot.com.co/2016/09/mexico-sa_12.html

Ferreyra, Gabriel, The Michoacanazo: A Case-Study of Wrongdoing in the Mexican Federal Judiciary, VIII Mexican Law Review, 1, 3-31 (2015). Disponible en: http://ac.els-cdn.com/S1870057815000025/1-s2.0-S1870057815000025-main. pdf?_tid=72e7cf04-ea6d-11e6-bb68-00000aacb35f\&acdnat $=1486166828 \_4 c 440$ c2703681a745e6bc28a436ef1a0

Flores-Martínez, Alejandra \& Uribe-Arzate, Enrique, La superación del monopolio proteccionista de los derechos humanos en el estado constitucional mexicano, a partir de la reforma al artículo primero constitucional, 129 Vniversitas, 103-134 (2014). Disponible en: http://revistas.javeriana.edu.co/index.php/vnijuri/article/ viewFile/11947/9782

Martínez, Francisco; Quintana, Luis \& Valencia, Rafael, Análisis macroeconómico de los efectos de la liberalización financiera y comercial sobre el crecimiento económico de México, 1988-2011, 23 Perfiles Latinoamericanos, 45, 79-104 (2015). Disponible en: http://www.flacso.edu.mx/publicaciones/revista_perfiles/Analisismacroeconomico-de-los-efectos-de-la-liberalizacion

Pegoraro, Lucio, Esiste un “diritto” a una buona amministrazione? (Osservazioni critiche preliminari sull' (ab) uso della parola "diritto"), 5-6 Istituzioni del Federalismo: rivista di studi giuridici e politici, 543-565 (2010). Disponible en: http://www. regione.emilia-romagna.it/affari_ist/Rivista_5_6_2010/Pegoraro.pdf

Ramírez-López, Lucía \& SÁnchez-Juárez, IsaAc Leobardo, Crecimiento económico, corrupción e instituciones en México, 22 Nóesis. Revista de Ciencias Sociales y 
Humanidades, 43-1, 104-133 (2013). Disponible en: http://erevistas.uacj.mx/ojs/ index.php/noesis/article/view/255/240

Ruiz-Torres, Miguel A. \& Azaola-Garrido, Elena, Cuadrar el delito. Corrupción institucional y participación de policías en el secuestro en México, 22 Perfiles Latinoamericanos, 44, 91-112 (2014). Disponible en: http://www.flacso.edu.mx/ publicaciones/revista_perfiles/Cuadrar-el-delito-Corrupcion-institucional-yparticipacion-de

Uribe-Arzate, Enrique \& Paz-GonzÁlez, Isaac de, The Constitutional Permeability Principle: Guidelines towards a Constructive Constitutional Theory in Mexico, 5 International Journal of Humanities and Social Science, IJHSS, 6, 21-27 (2015). Disponible en: http://www.ijhssnet.com/journals/Vol_5_No_6_June_2015/3.pdf

Zapata-Callejas, John Sebastián, La teoría del estado fallido: entre aproximaciones y disensos, 9 Revista de Relaciones Internacionales, Estrategia y Seguridad, 1, 87-110 (2014). Disponible en: http://revistas.unimilitar.edu.co/index.php/ries/ article/view/52

\section{Tratados internacionales}

Organización de Estados Americanos, OEA, Protocolo Adicional a la Convención Americana sobre Derechos Humanos en materia de Derechos Económicos, Sociales y Culturales, Protocolo de San Salvador, 17 de noviembre de 1988. Disponible en: http://www.oas.org/juridico/spanish/tratados/a-52.html

Organización de Naciones Unidas, ONU, Pacto Internacional de los Derechos Económicos, Sociales y Culturales, adoptado por la Asamblea General mediante la Resolución 2200A (XXI), 16 de diciembre de 1966. Disponible en: http://www. ohchr.org/SP/ProfessionalInterest/Pages/CESCR.aspx

Parlamento Europeo, Consejo de la Unión Europea y Comisión Europea, Carta de los Derechos Fundamentales de la Unión Europea (2000/C 364/01), Proclamación solemne, Diario Oficial de las Comunidades Europeas, 18 de diciembre de 2000. Disponible en: http://www.europarl.europa.eu/charter/pdf/text_es.pdf

\section{Normatividad mexicana}

México, Constitución, Diario Oficial de la Federación, 5 de febrero de 1917. Disponible en: http://www.diputados.gob.mx/LeyesBiblio/htm/1.htm

\section{Documentos, informes, reportes}

Banco Mundial, La violencia juvenil en México: Reporte de la situación, el marco legal y los programas gubernamentales (2012). Disponible en: http:// documentos.bancomundial.org/curated/es/277681468155375869/La-violenciajuvenil-en-Mexico-reporte-de-la-situacion-el-marco-legal-y-los-programasgubernamentales

Bingham, Tom, The Rule of Law (Centre for Public Law, The Sixth Sir David Williams 
Lecture, 16 ${ }^{\text {th }}$ November 2006). Disponible en: http://www.cpl.law.cam.ac.uk/ sir-david-williams-lectures/rt-hon-lord-bingham-cornhill-kg-rule-law

Canada, Institute on Governance, IOG, Public Sector Governance. Disponible en: http:// iog.ca/public-sector-governance/

Comisión Nacional de los Derechos Humanos, CNDH, Informe Especial Sobre los Grupos de Autodefensa y la Seguridad Pública en el Estado de Guerrero (México, 2008).

Der Spiegel Online, Teeth and Bones: Mass Abduction Reveals a Decaying Mexican State (Der Spiegel, 20 de noviembre de 2014). Disponible en: http://www. spiegel.de/international/world/mass-abductions-in-mexico-reveal-a-decayingstate-a-1003836.html

Duque-Roquero, Roberto \& Calero, Juandiego, Violómetro Constitucional (Centro de Investigación y Docencia Económicas, CIDE, Maestría en Periodismo y Asuntos Públicos del CIDE, Fundación Omidyar Network, México, s.f.). Disponible en: http://periodismocide.org/eventos/violometro/

ECHEBARRÍA, Koldo, Objetivar la gobernanza: funciones y metodología. Una aproximación a la objetivación del análisis institucional a través de indicadores de gobernabilidad (Ponencia presentada al IX Congreso Internacional del Centro Latinoamericano de Administración para el Desarrollo, CLAD, sobre la Reforma de Estado y de la Administración Pública, Madrid, 2-5, de noviembre de 2004). Disponible en: http://antigo.enap.gov.br/downloads/ec43ea4fObjetivarlagovernanza.pdf

MÉndez, JuAn E., Informe del Relator Especial sobre la tortura y otros tratos o penas crueles, inhumanos o degradantes. Adición Misión a México (2015). Disponible en: http://www.acnur.org/t3/fileadmin/Documentos/BDL/2015/9930.pdf?view=1

México, Cámara de Diputados, Auditoría Superior de la Federación, ASF, Análisis de la deuda pública de las entidades federativas y municipios (2012). Disponible en: http://www.asf.gob.mx/uploads/56_Informes_especiales_de_auditoria/1._ Analisis_de_Deuda_Publica_Agosto_2012.pdf

México, Cámara de Diputados, Gestión Financiera, Informe del resultado de la fiscalización superior de la cuenta pública 2013. Auditoría financiera y de cumplimiento: 13-0-01100-02-0038 (2013). Disponible en: http://www.asf.gob. $\mathrm{mx} /$ Trans/Informes/IR2013i/Documentos/Auditorias/2013_0038_a.pdf

México, Cámara de Diputados, LXI Legislatura, Arraigo judicial: datos generales, contexto y temas de debate, Carpeta de indicadores y tendencias sociales número 13 (México, noviembre de 2011). Disponible en: http://www3.diputados.gob.mx/ camara/content/download/269265/825108/file/Carpeta13_Arraigo_judicial.pdf

México, Instituto Nacional de Estadística, Geografía e Informática, INEGI, Encuesta Nacional de Victimización y Percepción sobre Seguridad Pública, ENVIPE(2016). Disponible en: http://www.beta.inegi.org.mx/proyectos/enchogares/regulares/ envipe/2016/

Organización de Naciones Unidas, ONU, Informe sobre Desarrollo Humano 2014, Sostener el Progreso Humano: Reducir vulnerabilidades y construir resiliencia (Programa de las Naciones Unidas para el Desarrollo, PNUD, Nueva York, 2014). Disponible en: http://www.undp.org/content/dam/undp/library/corporate/ HDR/2014HDR/HDR-2014-Spanish.pdf 
Organización de Naciones Unidas, ONU, What does Good Governance Mean? (September 2, 2012). Disponible en: http://unu.edu/publications/articles/whatdoes-good-governance-mean.html

Partlow, Joshua \& Martínez, Gabriela, Mexico's President Apologized for a Corruption Scandal. But the Nightmare goes on for the Reporter Who Uncovered it (The Washington Post, WorldViews, July 22, 2016). Disponible en: https://www. washingtonpost.com/news/worldviews/wp/2016/07/22/mexicos-presidentapologized-for-a-corruption-scandal-but-the-nightmare-goes-on-for-thereporter-who-uncovered-it/?utm_term $=.4 \mathrm{ae} 2 \mathrm{~d} 9274 \mathrm{ea} 4$

United Nations Educational, Scientific and Cultural Organization, UNESCO, Beyond 2015: Media as Democracy and Development (Paris, 2013). Disponible en: http://www.unesco.org/new/fileadmin/MULTIMEDIA/HQ/CI/CI/pdf/official_ documents/beyond_2015_media_democracy_development.pdf

United Nations International Children's Emergency Fund, UNICEF México, Pobreza $y$ desigualdad (Fondo de las Naciones Unidas para la Infancia, UNICEF). Disponible en: https://www.unicef.org/mexico/spanish/17046.html

WebBer, Jude, Murders ignored in Guerrero, says report (Financial Times, September 1, 2015). Disponible en: https://www.ft.com/content/aa7c5440-50da-11e5-b029b9d50a74fd14

\section{Jurisprudencia de la Corte Interamericana de Derechos Humanos, CorteIDH}

Corte Interamericana de Derechos Humanos, CorteIDH, Caso Jorge Castañeda-Gutman vs. México, Serie C 184, Excepciones preliminares, fondo, reparaciones y costas, sentencia de 6 de agosto de 2008. Disponible en: http://www.corteidh.or.cr/docs/ casos/articulos/seriec_184_esp.doc, http://www.ordenjuridico.gob.mx/JurInt/ STCIDHM01.pdf

Corte Interamericana de Derechos Humanos, CorteIDH, Caso González y otras (Campo Algodonero) vs. México, Serie C 205, Fondo, reparaciones y costas, sentencia de 16 de noviembre de 2009. Disponible en: http://www.corteidh.or.cr/docs/casos/ articulos/seriec_205_esp.pdf

Corte Interamericana de Derechos Humanos, CorteIDH, Caso Fernández-Ortega vs. México, Serie C 215, Fondo, reparaciones y costas, sentencia de 30 de agosto de 2010. Disponible en: http://www.corteidh.or.cr/docs/casos/articulos/ seriec_215_esp.pdf

Corte Interamericana de Derechos Humanos, CorteIDH, Caso Rosendo Radilla-Pacheco vs. México, Serie C 209, Excepciones preliminares, fondo, reparaciones y costas, sentencia de 23 de noviembre de 2009. Disponible en: http://www.corteidh.or.cr/ docs/casos/articulos/seriec_209_esp.pdf

Corte Interamericana de Derechos Humanos, CorteIDH, Caso Teodoro Cabrera-García y Rodolfo Montiel-Flores vs. México, Serie C 220, Excepción preliminar, fondo, reparaciones y costas, sentencia de 26 de noviembre de 2010. Disponible en: http://www.corteidh.or.cr/docs/casos/articulos/seriec_220_esp.pdf

Corte Interamericana de Derechos Humanos, CorteIDH, Caso Valentina Rosendo 
Cantú vs. México, Serie C 216, Excepción preliminar, fondo, reparaciones y costas, sentencia de 31 de agosto de 2010. Disponible en: http://www.corteidh. or.cr/docs/casos/articulos/seriec_216_esp.pdf

\section{Comisión Interamericana de Derechos Humanos, CIDH}

Comisión Interamericana de Derechos Humanos, CIDH, Caso Clara Gómez González y otros vs. México, Medidas cautelares, MC 423/14, 10 de octubre de 2014. Disponible en: https://www.oas.org/es/cidh/decisiones/pdf/2014/MC423-14-ES. pdf

Comisión Interamericana de Derechos Humanos, CIDH, Caso Estudiantes de la Escuela Rural Raúl Isidro Burgos vs. México, Medidas cautelares, MC 409/14, 3 de octubre de 2014. Disponible en: http://www.oas.org/es/cidh/decisiones/ pdf/2014/MC409-14-ES.pdf

Comisión Interamericana de Derechos Humanos, CIDH, Caso Margarita Marín-Yan y otros vs. México, Medidas cautelares, MC 29/16, 15 de abril de 2016. Disponible en: https://www.oas.org/es/cidh/decisiones/pdf/2016/MC29-16-Es.pdf

Comisión Interamericana de Derechos Humanos, CIDH, Informe de Grupo Interdisciplinario de Expertos Independientes, GIEI, convocado por la Comisión Interamericana de Derechos Humanos (México, 2015). Disponible en: http://www. oas.org/es/cidh/actividades/giei/GIEI-InformeAyotzinapa1.pdf, http://www.oas. org/es/cidh/actividades/giei/GIEI-InformeAyotzinapa2.pdf, http://www.oas.org/ es/cidh/actividades/giei.asp

\section{Jurisprudencia mexicana}

Suprema Corte de Justicia de la Nación, Pleno, Contradicción de tesis 293/2011, Resolución del 3 de septiembre de 2013. Disponible en: http://www2.scjn.gob. $\mathrm{mx} /$ asuntosrelevantes/pagina/seguimientoasuntosrelevantespub.aspx?id=1296 $59 \&$ seguimientoid $=556$

Suprema Corte de Justicia de la Nación, Segunda Sala, Jurisprudencia 56/2014 (10a.), 30 de abril de 2014, Gaceta del Semanario Judicial de la Federación, 772, Libro VI, 23 de mayo de 2014. Disponible en: http://sjf.scjn.gob.mx/sjfsist/Paginas/ wfDetalleTesis.aspx?SN=1\&Clase=DetalleTesisBL $\& I D=2006485 \&$ Expresion $=$ Jurisprudencia $\% 2056 / 2014 \% 2010$ a 